\title{
Bubbly Liquidity
}

\author{
EMMANUEL FARHI \\ Harvard University, Toulouse School of Economics, and NBER \\ and \\ JEAN TIROLE \\ Toulouse School of Economics
}

First version received January 2010; final version accepted June 2011 (Eds.)

\begin{abstract}
This paper analyses the possibility and the consequences of rational bubbles in a dynamic economy where financially constrained firms demand and supply liquidity. Bubbles are more likely to emerge, the scarcer the supply of outside liquidity and the more limited the pledgeability of corporate income; they crowd investment in (out) when liquidity is abundant (scarce). We analyse extensions with firm heterogeneity and stochastic bubbles.

Key words: Liquidity, Bubbles

JEL Codes: E2, E44
\end{abstract}

\section{INTRODUCTION}

Despite some progress in our understanding of asset price bubbles, many challenging questions are left unanswered. What role do macroeconomic conditions and financial institutions play in the emergence of bubbles? Is the classic theory of rational bubbles correct in predicting that bubbles raise interest rates and crowd out productive investment? ${ }^{1}$ Symmetrically, what are the consequences of bubble crashes? Do bubbles benefit/hurt some sectors more than others? What is the appropriate test for the existence of bubbles? Is there a link between dynamic inefficiency and the possibility of bubbles?

This paper investigates these questions by adding to the standard growth model an asynchronicity between firms' access to and need for cash. While this asynchronicity is perfectly resolved by capital markets in classic growth theory, capital markets here are imperfect: factors such as agency costs prevent firms from pledging the entirety of the benefits from investment to outside investors, resulting in credit rationing. The anticipation of credit rationing in turn gives rise to a familiar demand for liquidity (or stores of value; we will use the two terms interchangeably). Firms also supply liquidity by issuing securities, i.e. claims to their future revenues. Each firm is at times a net demander of liquidity or a net supplier of liquidity.

At the heart of this paper is the interplay between different forms of liquidity. Specifically, we investigate the interaction of inside liquidity (securities issued by financially constrained firms), outside liquidity (assets that originate in a different sector in the economy), and bubbles.

1. While the interest rate response is rather undisputed, some famous episodes seem consistent with a crowding in hypothesis. For example, Japan's bubble came with not only high interest rates but also vigorous investment and growth; when it bursts, the country went through a prolonged deflation and recession. Similarly, in the U.S., the Internet and housing bubbles were accompanied with economic booms; interest rates and investment fell when these bubbles burst. 
Literally speaking, bubbles are a form of outside liquidity, but because they are the focus of this paper, we choose to single them out.

The impact of outside liquidity on investment and economic activity accordingly hinges on the relative potency of two effects: a liquidity effect and a leverage effect. On the demand side, the firm's hoarding of liquidity makes them benefit from an increase in the supply and a reduction in the price of liquidity. On the supply side, their issuing securities to finance investment makes them vulnerable to high interest rate conditions: an increase in outside liquidity raises interest rates and competes with the securities issued by the firms, reducing their leverage.

This paper makes several contributions. First, as we just discussed, it studies the interplay between inside and outside liquidity. Outside liquidity helps firms address the asynchronicity between their access to and need for cash — the liquidity effect—-but also competes for savings with productive investment - the leverage effect. We show that the liquidity effect dominates when outside liquidity is abundant.

Second, this paper shows that bubbles are more likely to exist and can be larger when agency problems are severe (firms can only pledge a small fraction of their future revenues), outside liquidity is scarce and the demand for liquidity is high (the net worth of firms is high). ${ }^{2}$

Third, bubbles are a form of outside liquidity. They are more likely to crowd the financially constrained corporate sector's investment in (out), the more (less) abundant the outside liquidity.

Fourth, the crash of a bubble is accompanied by low interest rates and high leverage. It has a negative effect on firms' financial net worth and further reduces liquidity. Consequently, even in a risk-neutral environment, a stochastic bubble carries a liquidity premium (it features positive excess returns relative to the risk-free rate) since it pays little or zero in states where internal funds can be levered the most. Furthermore, bubble bursts can be endogenously triggered by adverse shocks to corporate net worth, resulting in a liquidity dry-up: financial disruptions amplify real disturbances.

Fifth, bubbles, and more generally outside liquidity, impact firms differently. Firms with limited ability to pledge future cash flows are little hit by competing claims as they issue no or few securities. They benefit more from a bubble. They are also more eager to hold stochastic bubbles.

Finally, in standard models of rational bubbles (e.g. Tirole, 1985), bubbles can occur only if the economy is dynamically inefficient so that tests aimed at detecting dynamic inefficiency can be used to determine if bubbles are possible. In our environment, Abel et al. (1989)'s finding that the productive sector disgorges at least as much as it invests does indicate that the economy is dynamically efficient. The possibility of bubbles is determined by the condition that the interest rate be higher than the growth rate of the economy, in conformity with Santos and Woodford (1997). ${ }^{3}$ But with imperfect capital markets, the economy can be dynamically efficient, and at the same time, the interest rate can be lower than the growth rate of the economy. This is because the social rate of return on internal funds exceeds that on borrowed funds; therefore, the social rate of return on investments is higher than the market interest rate when returns can be only imperfectly collateralized. As a result, bubbles are possible even when the economy is dynamically efficient. ${ }^{4}$

2. Accordingly, the much discussed "global savings glut" may have contributed to the recent housing bubble in the U.S. by creating a shortage of liquidity (stores of value). The low real interest rates that accompanied this episode are consistent with this narrative. To be certain, there are also other causes (failure of prudential regulation, etc.).

3. Moreover, our agency-based approach argues in favour of the use of (relatively low) interest rates received by outside investors such as the interest rate on riskless bonds.

4. Typically, bubbles do not lead to Pareto improvements. For example, the holders of outside liquidity in general lose from the emergence of a bubble, since the latter increases interest rates and lowers the price at which they can sell the outside liquidity. Similarly, equilibria with bubble crashes are usually not Pareto dominated by equilibria with no bubble crash. 
The paper proceeds as follows. Section 2 sets up the model and describes the solution when there are no bubbles. It characterizes its unique steady state and derives some key comparative statics results. Section 3 introduces the possibility of rational asset price bubbles. It derives the dynamics with bubbles and describes the properties of the unique bubbly steady state. Section 4 first analyses how bubbles affect the cross section of firms when there is heterogeneity in pledgeability; it then introduces stochastic bubbles and derives the mechanics of a bubbly boombust episode. Section 5 checks the robustness of the results in several variants of the model. Finally, Section 6 summarizes the main insights and discusses alleys for research. Most of the proofs are contained in the Appendix, as well as in an Online Appendix.

\subsection{Relation to the literature}

The paper builds on a number of contributions. Most obviously, it brings together the literature on (rational) bubbles and that on aggregate liquidity. The leverage effect, however, differs from the related competition effect featured in Diamond (1965)'s celebrated analysis of national debt and is prominent in the theory of rational bubbles (Tirole, 1985), whereby bubbles crowd investment out. The standard competition effect captures the idea that unconstrained firms want to invest less when interest rates are high. Our leverage effect has it that high interest rates aggravate credit rationing and so firms cannot invest as much. In particular, Diamond's competition effect is inconsistent with the existence of a liquidity effect.

The role of stores of values in supporting investment when income is not fully pledgeable has been stressed e.g. by Woodford (1990), Holmström and Tirole (1998), and a large recent literature, including independent contributions by Kiyotaki and Moore (2008) and Kocherlakota (2009). In Woodford's and Kocherlakota's contributions, which are most closely related to ours, firms are net demanders of liquidity and there is always a potential shortage of stores of value. These two papers assume that firms cannot supply liquidity (they have zero leverage) by positing that none of the future cash flow is pledgeable to investors and so firms do not issue securities. The possibility of leverage is central to many of our insights (existence of liquidity and leverage effects, conditions for the existence of bubbles, impact of bubbles on the cross section of firms). ${ }^{5}$

Saint-Paul (2005) shows that government debt (a store of value), while deterring capital accumulation, can increase the efficiency of the financial sector. Entrepreneurs can buy public debt and use it as collateral. The existence of collateral reduces agency costs (Saint-Paul uses the costly-state-verification model as an illustration). Accordingly, public debt boosts growth over a range of parameters.

The paper shares with Kiyotaki and Moore (1997) the idea that investment decisions are intertemporal complements. In Kiyotaki-Moore, tomorrow's investment will raise the price of the store of value, which is used as an input in the production process; this future increase in the price of the store of value raises the firms' wealth and thereby today's investment. In our paper, it is yesterday's investment that supports today's investment by creating securities that firms can hoard to meet their liquidity needs. Thus, Kiyotaki and Moore's dynamics are forward looking while ours are essentially backward looking (in the absence of bubbles). Also, Kiyotaki-Moore's focus is rather different as it has no bubbles.

The rational bubble literature has addressed the crowding-out critique in alternative ways. ${ }^{6}$ Bubbles are attached to investment in Oliver (2000) and to entrepreneurship in Ventura (2003),

5. As we show in Appendix A.3, the mechanism through which bubbles may crowd investment in is very different in our model and in Woodford (1990) or Kocherlakota (2009).

6. Other theories based on agency problems and asymmetric information as well as behavioural models have proliferated in recent years. A partial list includes Abreu and Brunnermeier (2003), Allen and Gale (2000), Allen and Gorton (1993), Allen, Morris and Postlewaite (1993), Barlevy (2009), Conlon (2004), Doblas-Madrid (2009), and 
generating an incentive and a wealth effect, respectively; in both papers, bubbles can crowd investment in. Saint-Paul (1992), Grossman and Yanagawa (1993), and King and Ferguson (1993) address the dynamic-efficiency critique by studying endogenous growth models with bubbles, in which the social return on investment exceeds the private return due to spillovers. ${ }^{7}$

Caballero and Krishnamurthy (2006) developed a theory of bubbles in emerging markets. They introduced, as we do, an investment-driven demand for liquidity and showed that in the presence of fragile (stochastic) bubbles, the economy overinvests in the bubbly asset and is overexposed to bubble crashes due to a pecuniary externality.

Our paper also sheds some light on the debate as to whether monetary authorities should try to lean against bubbles (or, in a more extreme form, try to make them pop) by raising interest rates or denying access to the discount window to banks that extend too many loans. Some scholars (e.g. Bernanke and Gertler, 2000, 2001; Bernanke, 2002; Gilchrist and Leahy, 2002) argue that the central bank should not pay attention to asset prices unless these signal future inflation; others (e.g. Bordo and Jeanne, 2002) are in favour of a moderate reaction. ${ }^{8}$ All concur that a restrictive policy leads to a lower output and a significant risk of collateral-induced credit crunch. Our model is consistent with this premise, as the pricking of the bubble leads to a collateral shortage and reduced investment and production.

Our paper is related to several strands of the monetary literature. It has been well-known since Allais (1947)'s and Samuelson (1958)'s seminal contributions that there exists economies in which money has a positive value in spite of the fact that it is intrinsically useless. ${ }^{9}$ In those models, money can be readily reinterpreted as a rational bubble, a fact long recognized in the rational bubbles literature. Our paper is also related to a more recent strand of the monetary theory literature often referred to as the New Monetarist literature. It emphasizes the role of money and other assets in overcoming trading frictions in economies with decentralized trade. Because of problems related to the double coincidence of wants, imperfect commitment, enforcement, and record keeping, unsecured credit is not viable and some trades must quid pro quo, involving either the sale of an asset or a collateralized loan. Such set-ups give rise to endogenous liquidity premia. Williamson and Wright (2011) and Nosal and Rocheteau (2011) provide excellent surveys. Most closely related to us is Rocheteau and Wright (2010). They build on the extension by Rocheteau and Wright (2005) of the model of Lagos and Wright (2005) and include endogenous participation decisions. Some of their results resemble ours. Indeed, in their model, liquid assets can trade above their fundamental value if the aggregate supply of liquid assets is low. They

Scheinkman and Xiong (2003). See LeRoy (2004) for a good survey. These theories typically reach more precise predictions than rational bubbles models regarding which assets are more likely to feature bubbles and have a rich array of implications for volume, turnover etc. However, these contributions have for the most part retained a more microeconomic focus and have not analysed the liquidity-provision function of bubbles.

7. The long-term rate of interest can then be smaller than the rate of growth of the economy, and yet the economy be dynamically efficient. However, the condition for the existence of bubbles is still determined by the condition that the growth rate of the economy be higher than the interest rate. Our results are reminiscent of their findings. However, in our paper, the reason that the social rate of return on investment is higher than the interest rate is fundamentally different: it does not stem from an externality in production but rather from an agency problem such as moral hazard or limited commitment. As a result, only a fraction of the return to investment can be pledged to outside investors, and the rest is appropriated by entrepreneurs (and more generally by insiders of the firm in a broader interpretation of the model). The interest rate reflects the fraction of the return to investment which is pledgeable to outside investors, whereas the social rate of return on investment accounts for the total return on investment-both the pledgeable part and the unpledgeable part which is appropriated by entrepreneurs.

8. This is only a partial list of references on the topic. See Adrian and Shin (2008) for a more complete list.

9. Overlapping generations models with money have been later thoroughly developed by Gale (1973), Cass, Okumo and Zilcha (1979), Wallace (1980), Hahn (1982), Balasko and Shell (1981), Grandmont (1985), among others. A textbook treatment can be found in Azariadis (1993). 
also generate multiple stationary equilibria where asset prices and output are positively related. Moreover, they also construct non-stationary equilibria, even when fundamentals are deterministic and non-stochastic. These include equilibria with price trajectories that resemble bubbles growing and bursting. An important difference with us is that, using the language of our model, they focus on liquidity effects and assume away leverage effects. ${ }^{10}$

\section{THE MODEL}

\subsection{Description}

2.1.1. Demographics, preferences, and technology. Our model has overlapping generations of risk-neutral entrepreneurs. The population is constant (all our results generalize to the case of positive population growth). Entrepreneurs live for three periods: young, middle-aged, and old. For simplicity, we assume that entrepreneurs consume only when old. They are risk neutral and seek to maximize expected consumption. Each generation is indexed by the period in which it is born. Time runs from $t=0$ to $t=\infty$. At each date $t=0,1, \ldots, \infty$, the economy is inhabited by the old (generation $t-2$ ), the middle-aged (generation $t-1$ ), and the young (generation $t$ ).

There is a single good in the economy. When young, entrepreneurs of generation $t$ are endowed with $A$ units of good (wealth). When middle-aged, they invest $i_{t+1}$ to produce $\rho_{1} i_{t+1}$ when old. However, only a fraction $\rho_{0} i_{t+1}<\rho_{1} i_{t+1}$ of the return on investment is pledgeable, where $\rho_{1}>\rho_{0}>0$.

2.1.2. Market for liquidity. In every period, a market for liquidity allows entrepreneurs to lend and borrow, subject to the borrowing constraints imposed by the limited pledgeability of their future income. The interest rate prevailing between date $t$ and date $t+1$ is $1+r_{t+1}$. In equilibrium, it will always be the case that the pledgeability parameter $\rho_{0}$ is strictly less than $1+$ $r_{t+1}$, otherwise middle-aged entrepreneurs could achieve an infinite investment scale. Because pledgeability is limited, firms can only partially rely on outside financing at the investment stage. We will only analyse equilibria where $\rho_{1}>1+r_{t+1}$ so that the investment opportunities of entrepreneurs are strictly positive net-present-value projects.

The ingredients that determine supply and demand in the market for liquidity are as follows. The asynchronicity between the availability of cash and investment opportunities, together with the imperfect pledgeability of cash flows from investment, lead to a demand for liquidity (stores of value) from young entrepreneurs: they purchase assets in their youth when they have wealth ${ }^{11}$ and sell them in their middle age when they have an attractive investment opportunity that can only be partially financed by the market. In turn, middle-aged entrepreneurs are also suppliers of liquidity: they supply assets which capitalize the pledgeable cash flows from their investment project.

At the heart of this paper is the interplay between different forms of liquidity. Specifically, we investigate the interaction of inside liquidity (assets produced by middle-aged entrepreneurs of generation $t$ when they pledge a fraction of the return on their investment project), outside liquidity (assets that originate in a different sector in the economy), and bubbles. Literally speaking, bubbles are a form of outside liquidity, but because they are the focus of this paper, we choose to single them out.

10. More precisely, the absence of leverage effects is tied to their assumption that shares in firms provide no liquidity service.

11. That the entrepreneurs are net savers when young follows Woodford (1990). The results, however, only hinge on their having a demand for liquidity available in their middle age. 
We model outside liquidity as follows. At each point of time $t$, there is a net supply of $l$ units of Lucas trees or "rents": date- $t$ trees each pay one unit of good at date $t+1$. These assets will be purchased in equilibrium by young entrepreneurs so as to be able to invest when middle-aged. We will focus on the case where $l \geq 0$. In extensions in Sections 5.1 and 5.3, we explain how in some cases it can make sense to examine the case $l<0$. Section 5.1 explains how our analysis differs in this case. At this stage, we only offer a simple model of the owners of these assets: they are completely passive and supply them inelastically: $l$ is just an exogenous supply and the focus is entirely on entrepreneurs. One possible micro-foundation is that at each date $t$, oneperiod-lived date- $t$ consumers are endowed with trees paying a dividend equal to $l$ at date $t+1$. These consumers live only in period $t$ and need to consume at that date. We will encounter in Section 5.3 other micro-foundations for outside liquidity in which $l$ may respond to the interest rate; as we will see, the theory extends to such situations.

Liquidity can also come in the form of a rational bubble. The bubble is an asset in unit supply that pays no dividend. We denote by $b_{t} \geq 0$, the value of the bubble at date $t$.

In the basic model, all these forms of liquidity-securities issued by middle-aged entrepreneurs, trees, and the bubble - are riskless assets. No arbitrage requires all these assets to have the same rate of return $1+r_{t+1}$ between dates $t$ and $t+1$.

2.1.3. The problem of entrepreneurs. Entrepreneurs invest all their wealth in their youth in assets - trees, the bubble, and investment projects of the previous generation - and use these savings when middle-aged as internal funds for their investment project. In their youth, entrepreneurs of generation $t$ must decide how much to spend $A_{t}^{l}$, on trees, how much $A_{t}^{b}$ of the bubble to acquire, and how much $A_{t}^{i}$ to invest in securities issued by entrepreneurs of generation $t-1$

$$
A=A_{t}^{l}+A_{t}^{b}+A_{t}^{i} .
$$

At date $t+1$, the total resources available for investment for date- $t$ entrepreneurs are the value of the claims on the future cash flows from their investment $\rho_{0} i_{t+1} /\left(1+r_{t+2}\right)$ and the date $t+1$ value of its portfolio of trees $A_{t}^{l}$, bubbles $A_{t}^{b}$, and securities $A_{t}^{i}$ issued by the previous generation of entrepreneurs. All these assets have the same return $1+r_{t+1}$. Hence,

$$
i_{t+1}=\frac{\rho_{0} i_{t+1}}{1+r_{t+2}}+\left(1+r_{t+1}\right)\left[A_{t}^{l}+A_{t}^{b}+A_{t}^{i}\right] \quad \text { or } \quad i_{t+1}=\frac{\left(1+r_{t+1}\right)\left[A_{t}^{l}+A_{t}^{b}+A_{t}^{i}\right]}{1-\frac{\rho_{0}}{1+r_{t+2}}} .
$$

As is standard from the corporate finance literature, investment $i_{t+1}$ increases with the entrepreneurs' net worth $\left(1+r_{t+1}\right)\left[A_{t}^{l}+A_{t}^{b}+A_{t}^{i}\right]$ at the time when the investment is made. The investment multiplier $1 /\left[1-\rho_{0} /\left(1+r_{t+2}\right)\right]$ is a measure of leverage. It increases with the fraction of income that is pledgeable to investors $\rho_{0}$ and decreases with the interest rate $1+r_{t+2}$ through the decrease in the value of the collateral generated by the project. ${ }^{12}$

2.1.4. Discussion. We have adopted a framework with overlapping generations of entrepreneurs. The concept of generation should not be interpreted too literally-a period in our

12. We also need to specify what happens with the initial middle-aged and the initial old entrepreneurs in period 0 . We assume that the initial old entrepreneurs have invested at scale $i_{-1}$ and pledged a fraction $\rho_{0} i_{-1}$ of this return in the form of securities issued to the inital middle-aged entrepreneurs. At date 0 , the value of the portfolio of the initial middle-aged entrepreneurs is equal to the sum of the value of the bubble $b_{0}$, the dividend $\rho_{0} i_{-1}$ on the securities issued by the initial old entrepreneurs, and the dividend $l$ on the trees. The resources available for investment for the initial middle-aged entrepreneurs in period 0 are the sum of the value of their portfolio and the value $\rho_{0} i_{0} /\left(1+r_{1}\right)$ of the securities that they sell to the initial young entrepreneurs. 
model need not last for 25 years. Rather, overlapping generations are the simplest modelling device that allows us to capture two features that are essential for our analysis. First, at any point of time, some entrepreneurs are net suppliers of liquidity while others are net demanders of liquidity. Second, interest rates can be lower than the rate of growth of the economy (here, zero), which makes room for rational bubbles.

Other modelling options would have delivered the same features. For example, we could have analysed a model à la Woodford (1990) where entrepreneurs are segmented into groups with alternating investment opportunities and borrowing constraints. Or we could have opted for a model à la Aiyagari (1994), Bewley (1986), and Hirano and Yanagawa (2010) where the investment opportunities of entrepreneurs are stochastic, with idiosyncratic risk (and possibly aggregate risk as well). Under both types of models, occasionally binding borrowing constraints segments the horizons of agents with essentially the same effects as overlapping generations.

The potential benefit of Aiyagari-Bewley models over ours is that they are in principle more suitable for realistic quantitative explorations. However, the parameters for a realistic calibration in the context of our model (i.e. a precautionary savings model for firms instead of the more customary income fluctuation problem for consumers) are currently largely unknown. Moreover, this benefit has to be weighted against the cost in terms of loss of tractability. Indeed, the dynamics of such models can be hard to characterize theoretically because of the need to keep track of the evolving cross-sectional distribution of wealth. By contrast, we are able to derive the solution of our model in closed form. Since our objective is mostly theoretical, we view our model as preferable.

\subsection{Competitive equilibrium}

A competitive equilibrium imposes market clearing: $A_{t}^{l}=l /\left(1+r_{t+1}\right), A_{t}^{b}=b_{t}$, and $A_{t}^{i}=$ $\rho_{0} i_{t} /\left(1+r_{t+1}\right)$. We will use a version of recursive equilibrium as our running definition. The economy is amenable to a recursive representation with two-state variables: past investment $i_{t-1}$ and the bubble $b_{t}$. The laws of motion for these variables can be derived from three simple equations: a bubble dynamics equation, an asset supply equation, and an asset demand equation.

2.2.1. Bubble dynamics. The absence of arbitrage implies that the bubble must grow at the rate of interest

$$
b_{t+1}=\left(1+r_{t+1}\right) b_{t}
$$

2.2.2. Asset supply. The supply equation describes how generation $(t-1)$ 's investment at date $t$ is constrained by the available liquidity, $l+b_{t}+\rho_{0} i_{t-1}$, and by the investment-related pledgeable income, $\rho_{0} i_{t} /\left(1+r_{t+1}\right)$,

$$
i_{t}=\frac{\rho_{0} i_{t}}{1+r_{t+1}}+\left[l+b_{t}+\rho_{0} i_{t-1}\right]
$$

and can be expressed as

$$
i_{t}=\frac{l+b_{t}+\rho_{0} i_{t-1}}{1-\frac{\rho_{0}}{1+r_{t+1}}}
$$

2.2.3. Asset demand. The demand equation says that generation $t$ 's wealth goes into buying outside liquidity $(l)$, the bubble, and the assets generated by the previous generation's 
investment $\left(\rho_{0} i_{t}\right)$

$$
A=\frac{l}{1+r_{t+1}}+b_{t}+\frac{\rho_{0} i_{t}}{1+r_{t+1}} .
$$

It can be expressed as

$$
i_{t}=\frac{A\left(1+r_{t+1}\right)-l-b_{t}\left(1+r_{t+1}\right)}{\rho_{0}} .
$$

We define a competitive equilibrium as a sequence of investment levels, bubble, and interest rates $\left\{i_{t}, b_{t}, r_{t}\right\}$ such that, at every date $t$, the asset market clears. We need to specify the following initial conditions: the investment level $i_{-1}$ of generation -1 maturing at date 0 and the value $b_{0}$ of the bubble at date 0 .

Definition 1. A competitive equilibrium is a sequence $\left\{i_{t}, b_{t}, r_{t}\right\}_{t \geq 0}$ together with an initial investment level $i_{-1}>0$ and an initial bubble $b_{0}$ such that: (i) the bubble condition (1), and the asset supply and asset demand equations (2) and (3) hold; (ii) for all $t \geq 0, i_{t} \geq 0, b_{t} \geq 0$, and $\rho_{1}>1+r_{t} \geq \rho_{0}$.

Note that in a competitive equilibrium, we necessarily have $1+r_{t}>\rho_{0}$ for all $t$, otherwise middle-aged entrepreneurs would invest at an infinite scale, which is impossible because the resources available for investment are bounded.

\subsection{The bubble-free case}

Let us first assume that $b_{0}=0$. This implies that $b_{t}=0$ for all $t$. The economy is a onedimensional dynamic system with state variable $i_{t-1}$. Given $i_{t-1}$, we now explain how $i_{t}$ can be computed using equations (2) and (3) with $b_{t}=0$. Detailed derivations can be found in Appendix A.1.

2.3.1. Dynamics. The asset supply equation (2) determines $i_{t}$ as a decreasing function of $r_{t+1}$, and the asset demand equation (3) determines $i_{t}$ as an increasing function of $r_{t+1}$. As $1+r_{t+1}$ increases from $\rho_{0}$ to $+\infty$, the supply curve decreases from $+\infty$ to $\left(l+\rho_{0} i_{t-1}\right)$ and the demand curve increases from $\left(A-l / \rho_{0}\right)$ to $+\infty$. The unique intersection of these supply and demand curves with $\left(1+r_{t+1}\right) \in\left(\rho_{0},+\infty\right)$ determines the values of $i_{t}>0$ and $1+r_{t+1}>$ $\rho_{0} \cdot{ }^{13}$ We denote by $i_{t}=\Phi^{i}\left(i_{t-1}, 0\right), r_{t+1}=\Phi^{r}\left(i_{t-1}, 0\right)$, the corresponding policy functions. The argument " 0 " in $\Phi^{i}\left(i_{t-1}, 0\right)$ and $\Phi^{r}\left(i_{t-1}, 0\right)$ indicates that we have imposed $b_{t}=0$. In Appendix A.1, we derive closed-form expressions for $\Phi^{i}\left(i_{t-1}, 0\right)$ and $\Phi^{r}\left(i_{t-1}, 0\right)$.

2.3.2. Inside and outside liquidity. The productive sector provides its own liquidity in a dynamic fashion: an increase in $i_{t-1}$ leads to an increase in $i_{t}$. Indeed, an increase in $i_{t-1}$ leads to an upward shift in the asset supply curve (2) and does not affect the asset demand curve (3). The result is an increase in investment $i_{t}$ and an increase in the interest rate $1+r_{t+1}$.

The asset supply and asset demand equations (2) and (3) can also be used to determine the impact of outside liquidity $(l)$ on investment $i_{t}$ for a given $i_{t-1}$ (see Figure 1). Given $i_{t-1}$, increasing outside liquidity $l$ shifts the asset supply curve (2) upwards and the asset demand curve (3) downwards. The interest rate $r_{t+1}$ unambiguously increases. The effect on investment $i_{t}$ is ambiguous. Indeed, using the asset supply equation $i_{t}=\left(l+\rho_{0} i_{t-1}\right) /\left[1-\rho_{0} /\left(1+r_{t+1}\right)\right]$,

13. This derivation assumes that $\rho_{1}$ is large enough so that $\rho_{1}>1+r_{t+1}$. As stated above, we focus on equilibria which verify this property. 


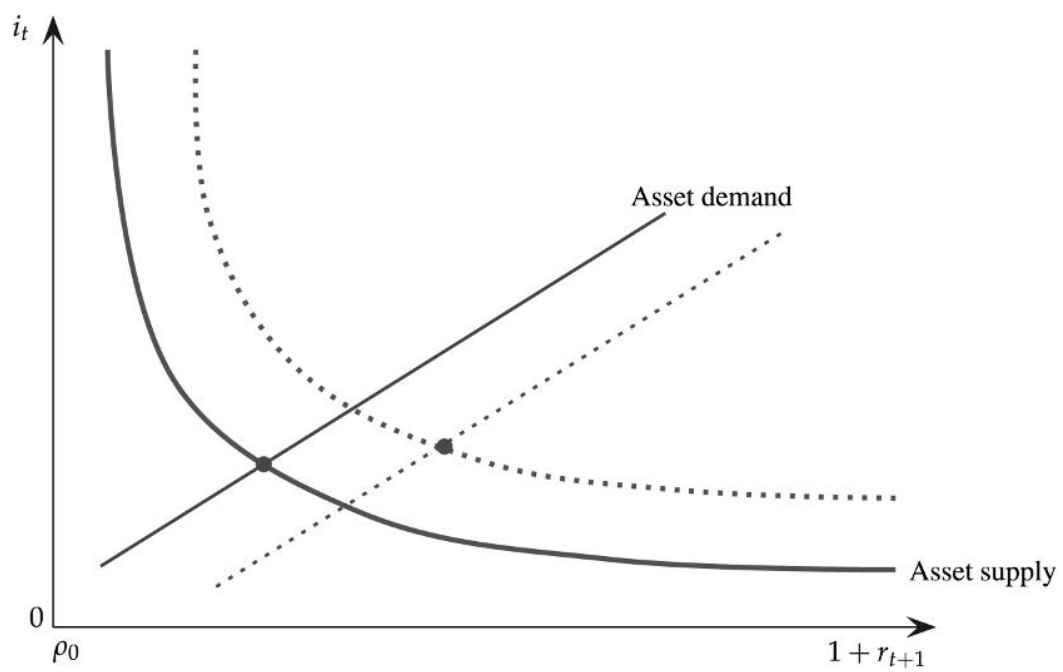

FIGURE 1

Asset supply and asset demand curves. The dotted curves represent the effects of an increase in $l$ (Section 2) or $b_{t}$

(Section 3)

the impact of the increase in outside liquidity on investment can be decomposed into two effects. On the one hand, increasing outside liquidity $l$ increases the net worth $l+b_{t}+\rho_{0} i_{t-1}$ of middleaged entrepreneurs at date $t$ - a liquidity effect. Also, and as noted above, increasing outside liquidity increases the interest rate $r_{t+1}$. As a result, leverage $1 /\left[1-\rho_{0} /\left(1+r_{t+1}\right)\right]$ decreases, which just expresses the fact that financing is harder when interest rates are high. This we call the leverage effect. The resulting effect on investment $i_{t}$ at date $t$ is ambiguous.

Intuitively, firms demand liquidity which is akin to an input in production. This tends to make investment and outside liquidity complements. But investments made by the private sector also play the role of inside liquidity. Inside liquidity is in direct competition with outside liquidity. This tends to make investment and outside liquidity substitutes. This distinction between the liquidity effect and the leverage effect also has a temporal dimension. Existing liquidityinside liquidity $i_{t-1}$ or outside liquidity $l$-and contemporaneous investment $i_{t}$ are complements. Future outside liquidity and contemporaneous investment $i_{t}$ are substitutes.

2.3.3. Steady state. To solve for a steady state $\left(i^{*}, r^{*}\right)$ of the bubble-free economy, we look for a solution to the system of equations obtained by imposing $i_{t}=i_{t-1}=i^{*}$ and $r_{t+1}=r^{*}$ in the asset supply and asset demand equations (2) and (3)

$$
i^{*}=\frac{l+\rho_{0} i^{*}}{1-\frac{\rho_{0}}{1+r^{*}}} \quad \text { and } \quad i^{*}=\frac{A\left(1+r^{*}\right)-l}{\rho_{0}} .
$$

There is a unique solution with $i^{*} \geq 0$ and $1+r^{*} \geq \rho_{0}$. In Appendix A.1, we provide a closedform solution for $i^{*}$ and $r^{*}$. The following proposition establishes that this steady state is stable and summarizes the dynamics of the bubble-free economy. ${ }^{14}$

14. When $l>0$ (this is also true of the case $l<0$ analysed in Section 5.1), this is the unique solution of the system of equations in (4) with positive investment $i^{*} \geq 0$. When $l=0$, there is another solution of the system of equations in (4) with positive investment: $i^{*}=0$ and $1+r^{*}=0$. However, this is not a competitive equilibrium, since a necessary condition is $1+r^{*}>\rho_{0}$. 
Proposition 1. Let $\left\{i_{t}, r_{t}\right\}_{t \geq 0}$ be a competitive equilibrium of the bubble-free economy. The economy converges to the bubble-free steady state. Moreover, this convergence is monotonic: investment $i_{t}$ converges monotonically to $i^{*}$.

We can clarify the circumstances under which outside liquidity and investment are complements or substitutes. The equations in (4) can be rearranged to yield

$$
i^{*}=\frac{A\left(1+r^{*}\right)}{1-\frac{\rho_{0}}{1+r^{*}}} .
$$

It can be verified that $i^{*}$ increases with $r^{*}$ if and only if the following condition holds:

$$
\frac{1}{2} \geq \frac{\rho_{0}}{1+r^{*}} .
$$

In Appendix A.1, we verify that $r^{*}$ increases with $l$. Hence, $i^{*}$ increases with $l$ if and only if $i^{*}$ increases with $r^{*}$ in equation (5), i.e. if and only if condition (6) holds. Given that $r^{*}$ is an increasing function of outside liquidity $l$, this condition will hold if $l$ is large enough. ${ }^{15}$ Let $l_{0}$ be the corresponding threshold. Clearly, $l_{0}>0$ if and only if condition (6) is violated when $l=0$ (in which case $1+r^{*}=\rho_{0} /\left(1-\rho_{0}\right)$ ), i.e. if and only if $1 / 2<\rho_{0}$.

Proposition 2. In the bubble-free economy, steady-state interest rate $r^{*}$ increases with outside liquidity. Steady-state investment $i^{*}$ increases with outside liquidity $l$ when the interest rate is high enough so that equation (6) is verified. More precisely, there exists $l_{0} \geq 0$ such that for all $l \geq 0, \frac{\partial i^{*}}{\partial l}$ is positive if and only if $l$ is greater (smaller) than $l_{0}$. Moreover, we have $l_{0}>0$ if and only if $\rho_{0}<1 / 2$.

This proposition characterizes the situations where inside liquidity (investment) and outside liquidity (trees) are complements or substitutes. When liquidity is abundant ( $l$ high), the price of liquidity is low (the interest rate $r^{*}$ is high) and the liquidity effect outweighs the leverage effect so that investment $i^{*}$ increases with $l$. An intuition for this result is that an increase in the interest rate $r^{*}$ has a constant positive marginal effect on net worth at the time of investment $A\left(1+r^{*}\right)$ but a decreasing negative marginal effect on leverage $1 /\left[1-\rho_{0} /\left(1+r^{*}\right)\right]$.

2.3.4. The case $\boldsymbol{l}=\mathbf{0}$. The case $l=0$ proves to be an important benchmark to understand the effects of bubbles. For this reason, we find it useful to highlight its properties even in the bubble-free case. The bubble-free steady state is then $i^{*}=A /\left(1-\rho_{0}\right)$ and $1+r^{*}=\rho_{0} /\left(1-\rho_{0}\right)$. In Appendix A.1, we show that whenever $l>0$, the steady-state interest rate is higher so that $1+r^{*}>\rho_{0} /\left(1-\rho_{0}\right)$.

\section{BUBBLES}

In this section, we consider the possibility of rational bubbles. We first start by eliciting the dynamics of the economy and the conditions for the existence of a bubbly steady state in Section 3.1. We show that there exists either zero or one bubbly steady state. This steady state features higher investment than the bubble-free steady state. There are multiple competitive equilibria corresponding to the same initial investment level $i_{-1}$. For any initial investment level $i_{-1}$, we

15. Indeed, $r^{*}$ goes to infinity as $l$ goes to infinity as can be seen from eliminating $i^{*}$ in equation (4) or from equation (A.6) in Appendix A.1. 
show that there exists a maximum feasible initial bubble $\bar{b}\left(i_{-1}\right)$. For $b_{0}<\bar{b}\left(i_{-1}\right)$, the economy converges to the bubble-free steady state. For $b_{0}=\bar{b}\left(i_{-1}\right)$, the economy converges to the bubbly steady state. Detailed derivations can be found in Appendix A.2 and its continuation in the Online Appendix A.2.

\subsection{Bubbly dynamics and steady state}

In this section, we focus on the case where $l>0$. We return to the case $l=0$ at the end of the section.

3.1.1. Dynamics. The economy is a two-dimensional dynamic system with state variables $i_{t-1}$ and $b_{t}$. Given $i_{t-1}$ and $b_{t}$, we now explain how $i_{t}$ and $b_{t+1}$ can be computed.

As can be seen from equation (3), a necessary condition for equilibrium is then that $b_{t}<$ $A$. The asset supply equation (2) determines $i_{t}$ as a decreasing function of $r_{t+1}$ and the asset demand equation (3) determines $i_{t}$ as an increasing function of $r_{t+1}$. As $1+r_{t+1}$ increases from $\rho_{0}$ to $+\infty$, the supply curve decreases from $+\infty$ to $\left(l+b_{t}+\rho_{0} i_{t-1}\right)$ and the demand curve increases from $\left(A-b_{t}-l / \rho_{0}\right)$ to $+\infty$. The unique intersection of these supply and demand curves with $\left(1+r_{t+1}\right) \in\left(\rho_{0},+\infty\right)$ determines the values of $i_{t}$ and $r_{t+1}$. See Figure 1 for a graphical illustration.

We can then infer the value of $b_{t+1}$ from equation (1). ${ }^{16}$ We denote by $i_{t}=\Phi^{i}\left(i_{t-1}, b_{t}\right)$, $r_{t+1}=\Phi^{r}\left(i_{t-1}, b_{t}\right)$, and $b_{t+1}=\Phi^{b}\left(i_{t-1}, b_{t}\right)$ the corresponding policy functions. In Appendix A.2, we derive closed-form expressions for $\Phi^{i}\left(i_{t-1}, b_{t}\right), \Phi^{r}\left(i_{t-1}, b_{t}\right)$, and $\Phi^{b}\left(i_{t-1}, b_{t}\right)$.

3.1.2. Bubbly steady state. There exists either zero or a unique bubbly steady state. When a bubbly steady state exists, the values of $i^{* *}, b^{* *}$, and $r^{* *}$ can be found by imposing $i_{t}=i_{t-1}=i^{* *}, b_{t}=b^{* *}$, and $r_{t+1}=r^{* *}=0$ in equations (2) and (3). See Figure 2 for a graphical illustration.

When it exists, the bubbly steady state is given by

$$
i^{* *}=\frac{A}{1-\rho_{0}}, \quad b^{* *}=A \frac{1-2 \rho_{0}}{1-\rho_{0}}-l, \quad \text { and } \quad r^{* *}=0 .
$$

The condition of existence of a bubbly steady state is

$$
\frac{1-2 \rho_{0}}{1-\rho_{0}}>\frac{l}{A}
$$

Condition (B) shows that bubbles can emerge when inside $\left(\rho_{0}\right)$ and outside $(l)$ liquidity is scarce, creating a high demand for assets. Moreover, the size of the bubble $b^{* *}$ in the bubbly steady state decreases with the fraction $\rho_{0}$ of income that is pledgeable and with outside liquidity $l$ : variations in $l$ are compensated one for one by variations in the size of the bubble. The interest rate $r^{* *}$ is pinned down at 0 . As a result, investment $i^{* *}$ at the bubbly steady state does not depend on $l$.

In Section 3.2, we show that condition (B) is equivalent to the standard condition that the interest rate in the bubble-free steady state $\left(r^{*}\right)$ be less than the rate of growth of the economy (0). There, we also analyse the connection between dynamic efficiency and the condition for the existence of bubbles.

16. This derivation assumes that $\rho_{1}$ is large enough so that $\rho_{1}>1+r_{t+1}$. As stated above, we focus on equilibria which verify this property. 


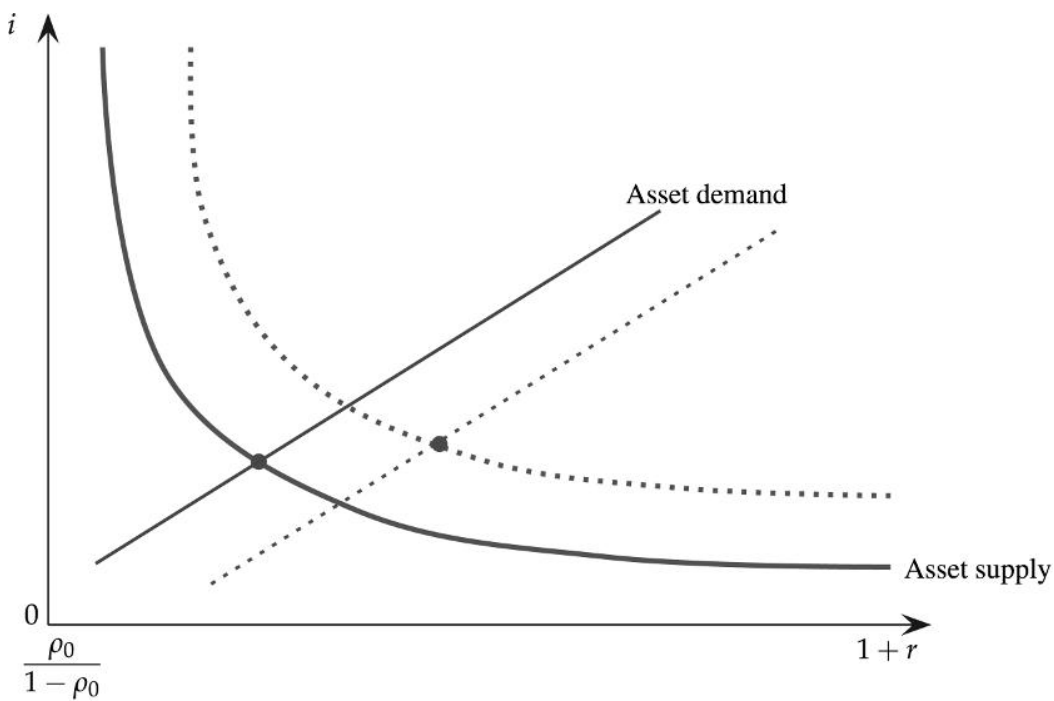

FIGURE 2

Asset supply and asset demand curves in steady state. The dotted curves represent the effects of an increase in $l$ (Section 2) or a shift from $b^{*}=0$ to $b^{* *}>0($ Section 3$)$

3.1.3. Phase diagram analysis. It will prove convenient to describe the dynamics that we have just derived using a phase diagram. This requires characterizing the $i_{t}=i_{t-1}$ schedulethe set of values $\left(i_{t-1}, b_{t}\right)$ such that $\Phi^{i}\left(i_{t-1}, b_{t}\right)=i_{t-1}$ —and the $b_{t+1}=b_{t}$ schedule - the set of values $\left(i_{t-1}, b_{t}\right)$ such that $\Phi^{b}\left(i_{t-1}, b_{t}\right)=b_{t} .{ }^{17}$

The $i_{t}=i_{t-1}$ schedule is given by

$$
b_{t}=i_{t-1}^{2} \frac{\rho_{0}\left(1-\rho_{0}\right)}{l}-\rho_{0} i_{t-1} \frac{A+\left(2-\frac{1}{r h o_{0}}\right) l}{l}-l
$$

which defines a function $b^{i}\left(i_{t-1}\right)$. The $b_{t+1}=b_{t}$ schedule is given by

$$
b_{t}=-\rho_{0}^{2} i_{t-1}+\left(1-\rho_{0}\right)(A-l)-\rho_{0} l,
$$

which defines a function $b^{b}\left(i_{t-1}\right)$.

Lemma 1. Suppose that $l>0$. The interest rate $r_{t+1}=\Phi^{r}\left(i_{t-1}, b_{t}\right)$ and investment $i_{t}=$ $\Phi^{i}\left(i_{t-1}, b_{t}\right)$ are increasing in $i_{t-1}$ and $b_{t}$. Investment $i_{t}=\Phi^{i}\left(i_{t-1}, b_{t}\right)$ is greater (smaller) than $i_{t-1}$ if and only if $b_{t}$ is greater (smaller) than $b^{i}\left(i_{t-1}\right)$. The bubble $b_{t}=\Phi^{b}\left(i_{t-1}, b_{t}\right)$ is greater (smaller) than $b_{t-1}$ if and only if $b_{t}$ is greater (smaller) than $b^{b}\left(i_{t-1}\right)$.

The intuition for this lemma is simple: the presence of the bubble lowers the price of outside liquidity or, in other words, increases the interest rate. This increases corporate net worth and investment to the detriment of the suppliers of outside liquidity.

17. Note that $b_{t+1}=b_{t}=0$ whenever $b_{t}=0$. Literally speaking, the $b_{t+1}=b_{t}$ schedule consists of two parts: the one characterized by $b_{t}^{b}\left(i_{t-1}\right)$ which applies whenever $b_{t}>0$, and the line $b_{t}=0$; abusing terminology, we refer to the former as the $b_{t+1}=b_{t}$ schedule. 


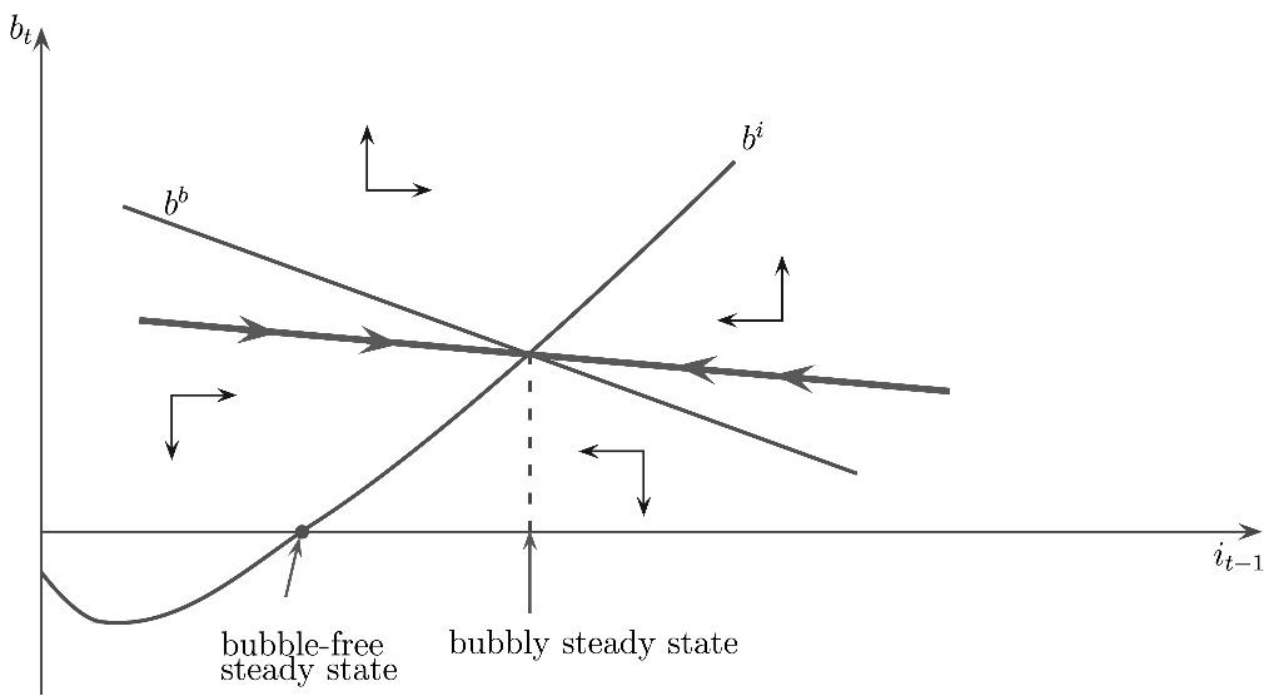

FIGURE 3

Phase diagram with positive outside liquidity

Figure 3 is a phase diagram representing the dynamics of the economy. ${ }^{18}$ The bubbly steady state always features more investment than the bubble-free steady state. The latter is stable while the former features a downward-sloping saddle path. If the economy starts on the saddle path, it will eventually converge to the bubbly steady state. If it starts below the saddle path, it will eventually converge to the bubble-free steady state. The economy cannot start above the saddle path without eventually violating the constraint $b_{t}<A$, which is a necessary condition for a competitive equilibrium.

Proposition 3. Assume that condition $(B)$ holds and that $l>0$. Then $r^{*}<0$ and $i^{* *}>i^{*}$. For any $i_{-1}$, there exists a maximum feasible bubble $\bar{b}\left(i_{-1}\right)$. The paths of productions/investments $\left\{i_{t}\right\}_{t \geq 0}$ and interest rates $\left\{r_{t}\right\}_{t \geq 0}$ are increasing in the size of the original bubble $b_{0}$. For $b_{0}<$ $\bar{b}\left(i_{-1}\right)$, the economy is asymptotically bubble free: it converges to the bubble-free steady state. For $b_{0}=\bar{b}\left(i_{-1}\right)$, the economy is asymptotically bubbly: it converges to the bubbly steady state. Moreover, the function $\bar{b}\left(i_{-1}\right)$ is decreasing in $i_{-1}$.

Remark 1. As is usual in rational bubbles models, our model features multiple equilibria. Absent additional structure, theory is agnostic as to equilibrium selection: it makes no prediction as to which equilibrium is more likely to be observed.

We are now in a position to describe the dynamics when a bubble unexpectedly bursts. We have in mind the following experiment. For $t<t_{0}$, the economy evolves as a competitive equilibrium $\left\{\tilde{l}_{t}, \tilde{b}_{t}, \tilde{r}_{t}\right\}_{t \geq 0}$ with $\tilde{b}_{t}>0$ for all $t$. Then at $t=t_{0}$, an unforeseen (zero probability) event materializes which changes the conditions in the economy: for $t \geq t_{0}$, the economy evolves according to the competitive equilibrium with initial conditions $i_{t_{0}-1}=\tilde{t}_{t_{0}-1}$ and $b_{t_{0}}=0$. In Section 4.2, we set up a sunspot model. The realization of the sunspot triggers a bubble crash.

18. We have $b^{i}(0)=-l<0$ and $b^{b}(0)=\left(1-\rho_{0}\right)(A-l)-\rho_{0} l$ which is strictly positive as long as condition (B) holds. It is easy to verify that $b^{i}$ is increasing when it intersects $b^{b}$. The sign of $\left.\frac{d b^{i}}{d i_{t-1}}\right|_{i_{t-1}=0}$, on the other hand, is unclear a priori. 
We construct a rational expectations equilibrium which takes into account that the bubble has a non-zero probability of crashing. The unexpected bubble burst that we consider here can be thought of as a limit of the sunspot model when the probability that the sunspot variable materializes goes to zero.

Suppose e.g. that we are initially in the bubbly steady state $\tilde{l}_{t}=i^{* *}, \tilde{b}_{t}=b^{* *}$, and $\tilde{r}_{t}=$ $r^{* *}=0$. When the bubble crashes at $t=t_{0}$, the economy jumps downwards to the $b_{t}=0$ line. Investment collapses, the interest rate decreases, and the economy gradually converges to the bubble-free steady state.

3.1.4. The case $\boldsymbol{l}=\mathbf{0}$. This analysis carries through to the case where $l=0$. The only difference is that the $i_{t}=i_{t-1}$ schedule becomes vertical at $i^{*}$. Investment dynamics are unaffected by the existence of a bubble

$$
i_{t}=A+\rho_{0} i_{t-1}
$$

The reason is that the sum of the value of the securities issued by the middle-aged generation, $\rho_{0} i_{t} /\left(1+r_{t+1}\right)$, and the bubble $b_{t}$ in the end is equal to the savings $A$ of the young generation. Put differently, the bubble fully crowds out the value of the assets produced by previous generations of entrepreneurs. Its only effect is to increase the rate of interest as

$$
b_{t}+\frac{\rho_{0} i_{t}}{1+r_{t+1}}=A
$$

Similarly, the bubbly steady state (if it exists) features the same investment level as the bubblefree steady state $i^{* *}=i^{*}=A /\left(1-\rho_{0}\right)$. At a steady state, the bubble simply increases the interest rate. ${ }^{19}$

\subsection{Tests for bubbles and dynamic efficiency}

To discuss efficiency, we first need a metric to index the welfare of the original holders of trees in every period. We take the utility of the original holders of date- $t$ trees to be (any increasing function of) the amount of resources that they receive from selling their trees. This is the right concept in the example we gave for the supply of outside liquidity with one-period-lived consumers in Section 2.

In our model, dynamic efficiency and Pareto efficiency are equivalent concepts and we therefore use the two terms interchangeably in what follows. An allocation is dynamically efficient if there is no other resource-feasible allocation that increases the lifetime utility of some agent without reducing that of another. Note that in this definition, the pledgeability constraints are deliberately ignored.

If an allocation is not dynamically efficient, we can ask whether it satisfies a weaker notion of efficiency which we refer to as constrained dynamic efficiency: an allocation is constrained dynamically efficient if there is no other resource-feasible allocation that increases the lifetime utility of some agent without reducing that of another, which satisfies the pledgeability constraints that require that the consumption of old entrepreneurs at date $t$ exceed $\left(\rho_{1}-\rho_{0}\right)$ times

19. Woodford (1990) shows that the introduction of bubbles always crowds investment in, starting in a situation where there are neither outside stores of value $(l=0)$ nor inside stores of value $\left(\rho_{0}=0\right)$. Because $\rho_{0}=0$, his model assumes away leverage effects. As we show here, with $\rho_{0}>0$, bubbles have no effect on investment if $l=0$. There is a discountinuity at $\rho_{0}=0$. See Appendix A.3 for a detailed discussion. 
the amount of resources that were invested at date $t-1$. Actually, we will show that competitive equilibria of our economy, when they are not dynamically efficient, are also not constrained dynamically efficient.

Determining whether an allocation is dynamically efficient is a simple task: when the pledgeability constraints are ignored, our economy is a simple overlapping generations economy with a linear investment technology with rate of return $\rho_{1}$. The following proposition demonstrates that the efficiency of the allocations that satisfy Definition 1 of a competitive equilibrium (and this definition does incorporate pledgeability constraints) hinges on the value $\rho_{1}$.

Proposition 4. If $\rho_{1}>1$, all competitive equilibria of our economy with or without bubbles are dynamically efficient. If $\rho_{1}<1$, no competitive equilibrium is constrained dynamically efficient.

Note that dynamic inefficiency $\left(\rho_{1}<1\right)$ implies that $r^{*}<0$. However, $r^{*}<0$ is compatible with dynamic efficiency $\left(\rho_{1}>1\right)$. Interest rates below the growth rate of the economy are compatible with dynamic efficiency because the interest rate reflects the fraction of the return on investment which is pledgeable to outside investors and not the total return on investment. Indeed, the paths for investment and the interest rate do not depend on the total return on investment $\rho_{1}$ (as long as $\rho_{1}>1+r_{t}$ for all $t$ ) but only on the pledgeable part of this return $\rho_{0}$. In sum, $r^{*}<0$ is a necessary but not sufficient condition for dynamic inefficiency.

Abel et al. (1989)'s test remains valid in our model as a test of dynamic efficiency, but it does not directly address the possibility of bubbles: dynamic inefficiency is a sufficient but not necessary condition for the possibility of bubbles. In contrast, the possibility of bubblescondition (B) —is still determined by the interest rate test $r^{*} \leq 0$.

Proposition 5. The possibility of bubbles is exactly determined by an (uninformed investor) interest rate test of the form $r^{*} \leq 0$.

At the bubbly steady state, the interest rate $r^{* *}$ is equal to 0 . Therefore, at a steady state, one can test for the possibility of bubbles by comparing the interest rate with the rate of growth of the economy, without taking a view as to whether or not the economy is at the bubble-free or bubbly steady state.

The validity of Abel et al. (1989)'s test to detect dynamic efficiency is most easily illustrated by applying it to steady states. Indeed, consider a (bubbly or bubble-free) steady state $(i, b) \in$ $\left\{\left(i^{*}, 0\right),\left(i^{* *}, b^{* *}\right)\right\}$. The test involves three quantities: the value of resources $\rho_{1} i$ produced in every period, the resources $i$ used for investment, and the value of the market portfolio $\rho_{0} i$. It states that the economy is dynamically efficient (inefficient) if and only if the difference between the resources produced and the resources used of investment normalized by the value of the market portfolio $\left(\rho_{1} i-i\right) /\left(\rho_{0} i\right)$ is strictly positive (negative), i.e. if and only if $\rho_{1}$ is greater (smaller) than 1, exactly as prescribed by Proposition 4 .

The considerations brought about by our analysis go part of the way towards rehabilitating interest rate tests as an indication for the possibility of bubbles. They shed light on which interest rate should be used in these tests: this rate corresponds to an interest rate available to outside investors-a relatively low interest rate such as the interest rate on riskless bonds.

\subsection{Summary}

Figure 4 allows for a concise summary of the dependence on outside liquidity $l$ of the bubbly and bubble-free steady states. The figure displays investment $i^{*}$ at the bubble-free steady state as a function of outside liquidity $l$. We denote this function by $i^{*}(l)$. We also use the notation $r^{*}(l)$ 


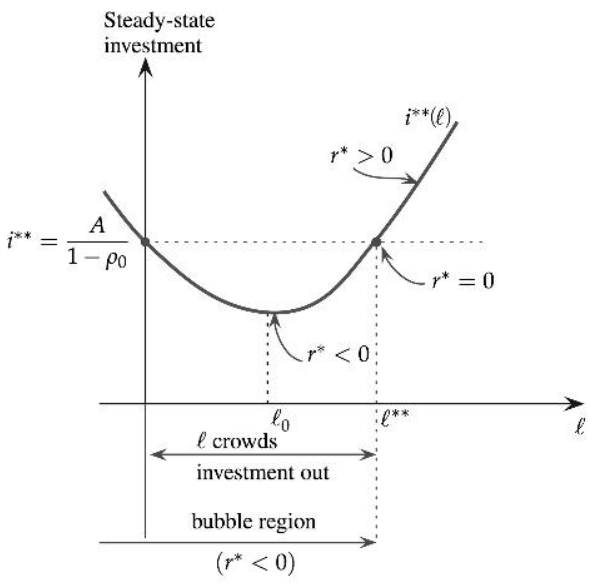

Case (i): $\rho_{0}<1 / 2$

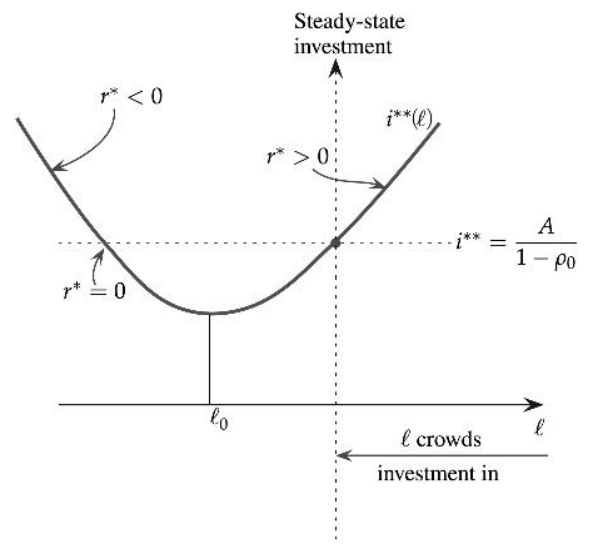

Case (ii): $\rho_{0}>1 / 2$

FIGURE 4

Comparing $\left(i^{* *}, r^{* *}\right)$ and $\left(i^{*}, r^{*}\right)$

to denote the interest rate in the bubble-free steady state. The figure also represents investment at the bubble-free steady state when $l<0$. This case will be covered later in Section 5.1. For now, we focus on the part of the figure that corresponds to $l \geq 0$.

The function $i^{*}(l)$ reaches a minimum on $[0,+\infty)$ at the threshold $l_{0} \geq 0$. In Proposition 2 , we showed that $l_{0}>0$ if and only if $\rho_{0}<1 / 2$. The left panel illustrates the case where $\rho_{0}<1 / 2$ (and hence $l_{0}>0$ ) and the right panel illustrates the case where $\rho_{0}>1 / 2$ (and hence $l_{0}=0$ ).

When $\rho_{0}>1 / 2$, liquidity always crowds investment in: $i^{*}(l)$ is increasing in $l$ for all $l \geq 0$. For all values $l \geq 0$, condition (B) is violated, and hence bubbles cannot arise.

In the rest of this section, we assume that $\rho_{0}<1 / 2$, liquidity crowds investment in (out) if and only if $l \geq l_{0}\left(l<l_{0}\right): i^{*}(l)$ decreases in $l$ on $\left[0, l_{0}\right]$ and increases in $l$ on $\left[l_{0}, \infty\right)$. There is always a value $l^{* *} \equiv A\left(1-2 \rho_{0}\right) /\left(1-\rho_{0}\right)>0$ such that $i^{*}\left(l^{* *}\right)=i^{*}(0)$.

Condition (B) holds, and hence bubbles can arise, if and only if $0 \leq l \leq l^{* *}$. At the bubbly steady state, variations in $l$ are compensated one for one by variations in the size of the bubble since $b^{* *}=A\left(1-2 \rho_{0}\right) /\left(1-\rho_{0}\right)-l$. As a result, investment $i^{* *}=A /\left(1-\rho_{0}\right)$ at the bubbly steady state does not depend on $l$. Importantly, investment at the bubbly steady state is always equal to investment at the bubble-free steady state when $l=0: i^{* *}=i^{*}(0)$.

When $l=l^{* *}$, investment is at the same level in the bubble-free and bubbly steady states: $i^{*}\left(l^{* *}\right)=i^{* *}=i(0)$. Moreover, the gross interest rate is equal to zero in the bubble-free steady state $1+r^{*}\left(l^{* *}\right)=0$, and the value of the bubble in the bubbly steady state is $b^{* *}=0$. For $0<l<l^{* *}$, investment is strictly higher in the bubbly steady state than in the bubble-free steady state $i^{* *}=i^{*}(0)>i^{*}(l)$. For $0 \leq l<l^{* *}$, the gross interest rate at the bubble-free steady state is strictly negative $\left(1+r^{*}(l)<0\right)$ and the size of the bubble at the bubbly steady state is given by $b^{* *}=l^{* *}-l>0$.

All in all, bubbles, when they are possible, always restore investment to the steady-state level corresponding to both $l=0$ and $l=l^{* *}: i^{* *}=i^{*}(0)=i^{*}\left(l^{* *}\right)$. When bubbles are possible, investment at the bubble-free steady state $i^{*}(l)$ initially decreases as outside liquidity increases from $l=0$ to $l=l_{0}$. Investment at the bubble-free steady state $i^{*}(l)$ then increases as outside liquidity increases from $l=l_{0}$ to $l^{* *}$ and reaches $i^{*}\left(l^{* *}\right)=i(0)$. For all $0<l<l^{* *}$, we have $i^{*}(l)<i^{* *}=i(0)=i\left(l^{* *}\right)$. For $l>l^{* *}$, bubbles cease to be possible. 


\section{ECONOMIC IMPLICATIONS}

\subsection{Collateral heterogeneity}

We have assumed so far for simplicity that firms are homogeneous (perhaps up to a scaling factor). When firms differ, say, in the pledgeability of their income, those with limited access to unsophisticated investors, i.e. low $\rho_{0}$ firms (family firms, private equity, startups), benefit relatively more from the presence of a bubble. They enjoy the liquidity effect without being much impacted by the leverage effect. Conversely, they also suffer more from a bubble crash.

Let $k$ be an index for firms and let $\rho_{0}^{k}$ be an increasing function of $k$. We can assume without loss of generality that $k$ is distributed uniformly on $[0,1]$. We denote by $i_{t}^{k}$ the investment of firm $k$ in period $t$ : each firm's investment is potentially different since they differ in their ability to generate pledgeable income $\rho_{0}^{k} i_{t}^{k}$ from investment. Importantly, all firms have the same initial net worth $A$, and hence the same wealth $b_{t}+l+\int \rho_{0}^{k} i_{t-1}^{k} d k$ when middle-aged, so that investment by firm $k$ is

$$
i_{t}^{k}=\frac{b_{t}+l+\int \rho_{0}^{k} i_{t-1}^{k} d k}{1-\frac{\rho_{0}^{k}}{1+r_{t+1}}}
$$

We then have the following aggregation result. The economy is described by two state variables: the value of the bubble $b_{t}$ and the integral $\int \rho_{0}^{k} i_{t-1}^{k} d k$ describing the total value of the existing stock of securities. The law of motion for $b_{t}$ is still $b_{t+1}=b_{t}\left(1+r_{t+1}\right)$, while $\int \rho_{0}^{k} i_{t-1}^{k} d k$ and $r_{t+1}$ are jointly determined as the intersection of the aggregate supply and the demand curves for assets ${ }^{20}$

$$
\int \rho_{0}^{k} i_{t}^{k} d k=\left(\int \frac{\rho_{0}^{k}}{1-\frac{\rho_{0}^{k}}{1+r_{t+1}}} d k\right)\left(b_{t}+l+\int \rho_{0}^{k} i_{t-1}^{k} d k\right)
$$

and

$$
\int \rho_{0}^{k} i_{t}^{k} d k=\left[A\left(1+r_{t+1}\right)-l-\left(1+r_{t+1}\right) b_{t}\right]
$$

There exists either zero or a unique bubbly steady state. When a bubbly steady state exists, the values of $\int \rho_{0}^{k} i^{* * k} d k$ and $b^{* *}$ can be found by imposing $\int \rho_{0}^{k} i_{t}^{k} d k=\int \rho_{0}^{k} i_{t-1}^{k} d k=\int \rho_{0}^{k} i^{* * k} d k$, $b_{t}=b^{* *}$, and $r_{t+1}=r^{* *}=0$ in equations (8) and (9). Investment $i^{* * k}$ by firm $k$ can then be computed using equation (7). We then have

$$
i^{* * k}=\frac{A}{1-\rho_{0}^{k}}, \quad b^{* *}=\left(\int \frac{1-2 \rho_{0}^{k}}{1-\rho_{0}^{k}} d k\right) A-l, \quad \text { and } \quad r^{* *}=0 .
$$

The condition for a bubble to exist is now given by

$$
\left(\int \frac{1-2 \rho_{0}^{k}}{1-\rho_{0}^{k}} d k\right)>\frac{l}{A}
$$

The analysis of the dynamics of the economy is exactly as in Section 3.1. Replacing the representative firm's pledgeable income by the industry-average pledgeable income, we see that the previous analysis generalizes to heterogenous firms.

20. Equations (8) and (9) are the same as equations (2) and (3) replacing $\rho_{0} i_{t}$ with $\int \rho_{0}^{k} i_{t}^{k} d k$ and $\frac{\rho_{0}}{1-\rho_{0} /\left(1+r_{t+1}\right)}$ by $\int \frac{\rho_{0}^{k}}{1-\rho_{0}^{k} /\left(1+r_{t+1}\right)} d k$. 
The relative size of firms with low pledgeable income increases when bubbles arise and decreases when bubbles crash. Taking derivatives in equation (7),

$$
\begin{aligned}
\frac{d i_{t}^{k}}{i_{t}^{k} d b_{t}} & =\frac{\partial i_{t}^{k}}{i_{t}^{k} \partial b_{t}}+\frac{\partial i_{t}^{k}}{i_{t}^{k} \partial r_{t+1}} \frac{d r_{t+1}}{d b_{t}} \\
& =\frac{1}{b_{t}+l+\int \rho_{0}^{k} i_{t-1}^{k} d k}-\frac{\rho_{0}^{k}}{\left(1+r_{t+1}-\rho_{0}^{k}\right)^{2}} \frac{d r_{t+1}}{d b_{t}} .
\end{aligned}
$$

We can also analyse the consequences of an unexpected (zero probability) bubble crash of the form discussed in Section 3.1. There are two immediate opposing effects on investment: (a) firms which used the bubble to hoard liquidity have less net worth and (b) the interest rate decreases, which allows for more leverage. The percentage decrease in investment resulting from a lower net worth is independent of $\rho_{0}^{k}$. The percentage increase in investment from a higher leverage is higher, the higher the pledgeable income $\rho_{0}^{k}$. As a result, in relative terms, the size of firms with low pledgeable income compared to the size of firms with high pledgeable income decreases when a bubble crashes.

Proposition 6. Assume that condition $\left(B^{\prime}\right)$ holds and that $l>0$. Then

(i) for any value of $\int \rho_{0}^{k} i_{-1}^{k} d k$, there exists a maximum feasible bubble $\bar{b}\left(\int \rho_{0}^{k} i_{-1}^{k} d k\right)$. The path of interest rates $\left\{r_{t}\right\}_{t \geq 0}$ is increasing in the size of the initial bubble $b_{0}$; the path of productions/investments $\left\{i_{t}\right\}_{t \geq 0}$ is increasing in the size of the initial bubble $b_{0}$. For $b_{0}<$ $\bar{b}\left(\int \rho_{0}^{k} i_{-1}^{k} d k\right)$, the economy is asymptotically bubble free: it converges monotonically to the bubble-free steady state. For $b_{0}=\bar{b}\left(\int \rho_{0}^{k} i_{-1}^{k} d k\right)$, the economy is asymptotically bubbly: it converges monotonically to the bubbly steady state;

(ii) the equilibrium paths for $\left\{b_{t}\right\}_{t \geq 0}$ and $\left\{r_{t}\right\}_{t \geq 0}$ are increasing in the size $b_{0}$ of the initial bubble;

(iii) the relative size of firms with low pledgeable income (low $\rho_{0}^{k}$ ) compared to the size of firms with high pledgeable income (high $\rho_{0}^{k}$ ) increases with the size of the initial bubble $b_{0}$ : the relative variation $\left(i_{t}^{k}\right)^{-1} d i_{t}^{k} / d b_{0}$ of investment $i_{t}^{k}$ at date $t+1$ with respect to the initial bubble $b_{0}$ is decreasing in $k$.

\subsection{Stochastic bubbles (1): bubbly liquidity premium}

As in Weil (1987), we can allow the bubble to burst stochastically depending on the realization of a sunspot. Suppose that each period the bubble bursts with probability $1-\lambda$. An asset's liquidity service depends on what the asset delivers when cash is particularly valuable to firms. Building on this idea, we now argue that, even in this risk-neutral environment, a stochastic bubble trades at a liquidity discount or equivalently a risk premium relative to riskless stores of value. We focus on the case $l>0$.

Let $i_{t}$ and $r_{t+1}$ (respectively, $i_{t}^{-}$and $r_{t+1}^{-}$) denote the investment levels and interest rates when the bubble has lasted until period $t+1$ and continues (respectively, bursts). The asset supply equations are given by

$$
i_{t}=\frac{b_{t}+l+\rho_{0} i_{t-1}}{1-\frac{\rho_{0}}{1+r_{t+1}}} \quad \text { and } \quad i_{t}^{-}=\frac{l+\rho_{0} i_{t-1}}{1-\frac{\rho_{0}}{1+r_{t+1}^{-}}} .
$$

Similarly, the asset demand equations are given by

$$
i_{t}=\frac{A\left(1+r_{t+1}\right)-l-\left(1+r_{t+1}\right) b_{t}}{\rho_{0}} \quad \text { and } \quad i_{t}^{-}=\frac{A\left(1+r_{t+1}^{-}\right)-l}{\rho_{0}} .
$$


Since $i_{t}^{-}$and $r_{t+1}^{-}$are determined by the same set of equations as $i_{t}$ and $r_{t+1}$ but with $b_{t}=0$, it is clear that $r_{t+1}>r_{t+1}^{-}$: the burst of the bubble depresses the interest rate. The immediate response of investment $i_{t}$ to a bubble crash is determined by Lemmas 1 and 3 (Online Appendix): as long as $l>0$, the burst of the bubble depresses investment so that $i_{t}>i_{t}^{-}\left(i_{t}=i_{t}^{-}\right.$when $\left.l=0\right)$.

At date $t$, generation- $t$ entrepreneurs can hold safe assets (trees, claims on previous investments' income) or risky ones (stochastic bubble). Letting $\widetilde{r}_{t}$ denote the return on the bubble when it does not burst: $b_{t}=\left(1+\tilde{r}_{t}\right) b_{t-1}$ if the bubble does not burst and $b_{t}=0$ otherwise. By investing one in a tree at $t$, an entrepreneur can secure $1+r_{t}$ at $t+1$, which allows him to invest $\left(1+r_{t}\right) /\left[1-\rho_{0} /\left(1+r_{t+1}\right)\right]$ at $t+1$ if the bubble does not crash at $t+1$ and $\left(1+r_{t}\right) /\left[1-\rho_{0} /\left(1+r_{t+1}^{-}\right)\right]$if it crashes. This allows him to consume $\left(\rho_{1}-\rho_{0}\right)\left(1+r_{t}\right) /$ $\left[1-\rho_{0} /\left(1+r_{t+1}\right)\right]$ at $t+2$ if the bubble does not crash at $t+1$ and $\left(\rho_{1}-\rho_{0}\right)\left(1+r_{t}\right) /[1-$ $\left.\rho_{0} /\left(1+r_{t+1}^{-}\right)\right]$if it crashes. Similarly, investing one in the bubble at $t$ delivers $1+\tilde{r}_{t}$ at $t+1$ if the bubble does not crash at $t+1$ and zero if it crashes. This allows the entrepreneur to invest $\left(1+\tilde{r}_{t}\right) /\left[1-\rho_{0} /\left(1+r_{t+1}\right)\right]$ at $t+1$ if the bubble does not crash at $t+1$ and zero if it crashes. This allows him to consume $\left(\rho_{1}-\rho_{0}\right)\left(1+\tilde{r}_{t}\right) /\left[1-\rho_{0} /\left(1+r_{t+1}\right)\right]$ at $t+2$ if the bubble does not crash at $t+1$ and zero if it crashes. In equilibrium, expected consumption at $t+2$ from these two investment options at $t$ must be equalized. This leads to the following arbitrage equation between bubbles and trees:

$$
\lambda \frac{1+r_{t}}{1-\frac{\rho_{0}}{1+r_{t+1}}}+(1-\lambda) \frac{1+r_{t}}{1-\frac{\rho_{0}}{1+r_{t+1}^{-}}}=\lambda \frac{1+\widetilde{r}_{t}}{1-\frac{\rho_{0}}{1+r_{t+1}}} .
$$

This in turn implies that $1+\widetilde{r}_{t}>\left(1+r_{t}\right) / \lambda$. Despite risk neutrality, stochastic bubbles feature a liquidity premium: they command positive net excess returns $\lambda\left(1+\widetilde{r}_{t}\right)-\left(1+r_{t}\right)$. The intuition is straightforward. Bubbles deliver no return when internal wealth is the most valuable: when liquidity is scarce, interest rates are low and internal funds can be levered a lot.

There are multiple equilibria with such stochastic bubble, exactly as in our baseline model. There exists a unique conditional bubbly steady state: a competitive equilibrium such that the variables $\left(i_{t}, b_{t}\right)$ are constant and equal to $\left(i^{* *}, b^{* *}\right)$ with $b^{* *}>0$ until the sunspot variable realizes and the bubble crashes. At such a conditional steady state, the bubble is constant (until it crashes) and hence $1+\widetilde{r}^{* *}=1$. Moreover,

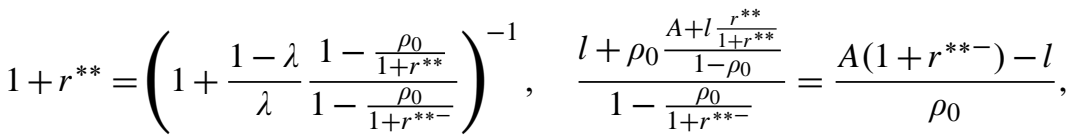

$$
\begin{aligned}
& i^{* *}=\frac{A+l \frac{r^{* *}}{1+r^{* *}}}{1-\rho_{0}}, \quad \text { and } \quad b^{* *}=\frac{A+l \frac{r^{* *}}{1+r^{* *}}}{1-\rho_{0}}\left(1-\frac{\rho_{0}}{1+r^{* *}}-\rho_{0}\right)-l \text {. }
\end{aligned}
$$

The condition for the existence of a bubble becomes ${ }^{21}$

$$
\frac{1-\frac{\rho_{0}}{1+r^{* *}}-\rho_{0}}{1-\rho_{0}}>\left[\frac{1}{1+\frac{l}{A} \frac{r^{* *}}{1+r^{* *}}}\right] \frac{l}{A} \text {. }
$$

21. Unfortunately, this condition determines only implicitly the parameter region that leads to the possibility of bubbles. It features an endogenous object $r^{* *}$. This complication arises for the following reason. Bubbles now present a risk premium and thus a positive net excess return: $\lambda\left(1+\tilde{r}^{* *}\right)-\left(1+r^{* *}\right)>0$. In a conditional bubbly steady state, zero bubble growth pins down the expected return on bubbles: $1+\tilde{r}^{* *}=1$, but the risk-free rate $r^{* *}$ has to be determined jointly with $r^{* *-}$ as solutions to a non-linear system. 
This condition is more likely to be verified, the higher $r^{* *}$ is. It coincides with condition (B) when $r^{* *}=0$. Note that we necessarily have $\left(1+r^{* *}\right) / \lambda<1+\tilde{r}^{* *}=1$ so that $r^{* *}<\lambda-1<0$. As a result, condition $\left(\mathrm{B}^{\prime \prime}\right)$ is more stringent than condition (B).

Proposition 7. Suppose that condition $\left(B^{\prime \prime}\right)$ holds and that $l>0$, then

(i) in any competitive equilibrium with a strictly positive bubble, before the bubble bursts, the bubble features a liquidity premium;

(ii) in any competitive equilibrium with a strictly positive bubble, the bursting of the bubble decreases interest rates: firms scramble for collateral, which becomes more valuable;

(iii) in any competitive equilibrium, when the bubble bursts, investment immediately decreases; then, the economy gradually converges to the bubble-free steady state;

(iv) in the conditional bubbly steady state-before the bubble bursts-as the probability of bursting $(1-\lambda)$ increases, the interest rate $r^{* *}$ and the bubble $b^{* *}$ decrease; investment $i^{* *}$ decreases;

(v) in the conditional bubbly steady state, interest rates and investment are high $\left(r^{* *}>r^{*}\right.$ and $i^{* *}>i^{*}$.

For example, when $l>0$, steady-state investment $i^{* *}$, bubble size $b^{* *}$, and interest rate $r^{* *}$ all decrease in the probability $1-\lambda$ that the bubble crashes. A more stable bubble provides more liquidity and is more conducive to investment. This in turn boosts the demand for liquidity and makes for a larger bubble.

A full characterization of the dynamics is outside the scope of this paper. Indeed, an extra state variable is required to describe the economy. The state space is now given by the triple $\left(i_{t-1}, b_{t}, r_{t}\right)$. The reason past interest rates $r_{t}$ have to be kept track of is that the arbitrage equation (10) involves both the interest rate at date $t$ and at date $t+1$. As a consequence, simple twodimensional phase diagrams cannot be used anymore. A full characterization of the stability properties of the different steady states and their basin of attraction is rather involved and outside the scope of this paper.

Remark 2. Imagine that there is a stochastic bubble in an economy with heterogeneity in pledgeable income as in Section 4.1. Equation (10) has the implication that firms with higher $\rho_{0}^{k}$ will demand a higher expected return to hold the bubble: they are more affected by the double whammy associated with a bubble crash (the loss of wealth at the moment when levering up is attractive). Therefore, in equilibrium, the bubble will be held by the firms with the lowest $\rho_{0}^{k} .{ }^{22}$ When $l>0$, we showed in Proposition 6 that for a given portfolio, these firms are also the firms whose investment decreases the most in percentage terms when the bubble crashes. The result is an amplification mechanism whereby the equilibrium allocation of the bubble across firms magnifies the impact of a crash. In equilibrium, firms with a high $\rho_{0}^{k}$ do not hold the bubble so that their net worth is insulated from the bubble crash. Moreover, they can increase their leverage more than firms with a low $\rho_{0}^{k}$ in response to the drop in interest rates that follows the crash of the bubble. Conversely, firms with a low $\rho_{0}^{k}$ hold the bubble so that their net worth is impaired when the bubble crashes. In addition, their leverage increases less than firms with a high $\rho_{0}^{k}$ in response to the drop in interest rates that follows the crash of the bubble.

22. Interestingly, the recent real estate crash did affect many highly levered financial institutions. The prospect of a public bailout (more likely for levered financial institutions), however, is not part of our competitive equilibrium modelling. 


\subsection{Stochastic bubbles (2): endogenous crashes}

Following up on Section (4.2), we modify the environment in the following way. Suppose that $A$ follows a two-state Markov process $A \in\left\{A_{H}, A_{L}\right\}$ with $A_{H}>A_{L}$. Initially $A=A_{H}$. With probability $1-\lambda>0$ per period, $A$ transitions to $A_{L}$ which is an absorbing state.

We assume that condition $\left(\mathrm{B}^{\prime \prime}\right)$ is verified for an exogenous bursting probability $(1-\lambda)$ in an economy with a deterministic and constant $A$ equal to $A_{H}$. Similarly, we assume that for any $\lambda \in[0,1]$, condition (B) is violated in an economy with a deterministic and constant $A$ equal to $A_{L}$. Hence, if the economy is already in the state of low net worth $A=A_{L}$, the demand for liquidity is low, the interest rate is high, and bubbles cannot exist. Bubbles, however, can exist as long as net worth is high: $A=A_{H}$.

Suppose that $A_{t}=A_{H}$ and consider the economy entering period $t+1$ with state variables given by $\left(b_{t}, i_{t-1}, r_{t}\right)$. Then if $A_{t+1}=A_{H},\left(b_{t+1}, i_{t}, r_{t+1}\right)$ are given by the same equations as in Section 4.2 with $A=A_{H}$. On the other hand, if $A_{t+1}=A_{L}$, then the bubble bursts: $b_{t}=0$ and $i_{t}$ are given by the same equations as above with $A=A_{L}$ and $b_{t}=0$. The economy then evolves as in Section 2.2.

Proposition 8. Assume that condition ( $\left.B^{\prime \prime}\right)$ holds with $A=A_{H}$ but that condition $(B)$ is violated with $A=A_{L}$. Consider an economy where in the initial period the economy is in steady state along the bubbly path and $A_{t}=A_{H}$. In the first period where $A_{t}=A_{L}$, the bubble bursts. Then the economy converges to the bubble-free steady state corresponding to $A=A_{L}$.

The mechanics of a bubble crash are similar to those of the previous section. The difference is that in Section 4.2, the burst of the bubble was triggered by the realization of a pure sunspot variable. Here, by contrast, the burst of the bubble is triggered by an adverse fundamental shock to initial net worth $A$ of entrepreneurs. When this shock occurs, the demand for liquidity drops enough that bubbles are not feasible anymore.

This environment makes clear that when $l>0$, bad shocks to corporate balance sheets can potentially have an amplified negative effect on investment over and above that described in the literature emphasizing the importance of corporate net worth—e.g. Bernanke and Gertler (1989) and Kiyotaki and Moore (1997) — by triggering liquidity dry-ups in the form of bubble bursts.

\section{DISCUSSION AND ROBUSTNESS}

\subsection{Negative outside liquidity}

We now assume that net outside liquidity $l$ is negative. This can be motivated by imagining that there is a demand for outside liquidity from an unmodelled part of the economy (another group of consumers or foreigners) who demand liquidity in excess of the supply of trees. This is relevant in light of the recent literature on the "global savings glut" (see for example Bernanke, 2005; Caballero et al., 2008a,b). We develop some of these ideas in Section 5.3.

We focus on steady states. Detailed derivations, as well as an analysis of the dynamics, can be found in Appendices A.1, A.2, and A.4.

5.1.1. Steady states. There is a unique bubble-free steady state which corresponds to the intersection of the $b_{t}=0$ locus with $i_{t}=i_{t-1} \geq 0$; this steady state is always stable. ${ }^{23}$ If condition (B) holds, there are two intersections between the $i_{t}=i_{t-1}$ and the $b_{t+1}=b_{t}$ schedules such

23. We have $b^{i}(0)=-l>0$ and $b^{b}(0)=\left(1-\rho_{0}\right)(A-l)$ which is strictly positive as long as condition (B) holds. 
that $b_{t}>0$. The corresponding investment levels are given by $-l\left(1-\rho_{0}\right) / \rho_{0}$ and $A /\left(1-\rho_{0}\right)$. As long as the following condition is satisfied, the lowest solution corresponds to an unstable bubbly steady state and the highest solution to a saddle-path-stable bubbly steady state

$$
-\frac{l}{A}<\frac{\rho_{0}}{\left(1-\rho_{0}\right)^{2}}
$$

Condition (11) is more likely to be verified; the lower the net demand $-l$ for outside liquidity, the higher the level of pledgeable income $\rho_{0}$ and the higher the net worth of entrepreneurs $A$. We maintain it throughout this section.

Proposition 9. Suppose that $l<0$, then

(i) $r^{*}$ increases with $l$; steady state investment $i^{*}$ increases with $l$ when the interest rate is high enough so that equation (6) is verified; more precisely, there exists $\tilde{l}_{0}$ such that for all $l, \frac{\partial i^{*}}{\partial l}>0$ if and only if $l>\tilde{l}_{0}$; moreover, we have $\tilde{l}_{0}>0$ if and only if $\rho_{0}<1 / 2$;

(ii) suppose that condition (B) and equation (11) hold, then investment at the bubbly steady state is lower than investment at the bubble-free steady state $i^{* *}=A /\left(1-\rho_{0}\right)<i^{*}$;

(iii) suppose that equation (11) holds, then the results in Propositions 4 and 5 extend to the case $l<0$.

The first part of the proposition focuses on the question of whether outside liquidity crowds investment in or out at the bubble-free steady state. This result generalizes that of Proposition 2: outside liquidity crowds investment in when outside liquidity is abundant enough.

The second part of the proposition focuses on the question of whether bubbles crowd investment in or out by comparing the bubble-free and bubbly steady states. Bubbles always increase interest rates, which reduces the value of the trees. When $l>0$, the non-corporate sector is a net seller of trees. The bubble then operates a transfer from the non-corporate sector to the corporate sector, which increases investment. Bubbles and investment are complements. When $l<0$, the opposite happens and bubbles crowd investment out. Bubbles and investment are then substitutes. Figure 4 provides a convenient summary.

The third part of the Proposition shows that both our efficiency results in Proposition 5 and our results for the interest rate test to infer the possibility of bubbles in Proposition 4 generalize to the case $l<0$.

Remark 3. Entrepreneurs' preferences were chosen such that they save their entire endowment when young and invest all the resulting wealth when middle-aged. The Online Appendix A.4 relaxes this assumption and allows more flexibility in the entrepreneurs' savings/dissavings choices. It turns out that the results obtained in this paper carry over with the one following caveat. Once we allow for flexibility in the entrepreneurs savings/dissavings choices, it is still true that bubbles boost investment when outside liquidity $l$ exceeds some threshold; this threshold need not be equal to zero and instead may either be positive or negative.

\subsection{Public debt as outside liquidity}

In a non-Ricardian environment, public debt can be a form of outside liquidity. Indeed, imagine that there are consumers who live for one period, receive income $w$. Imagine that the government taxes a portion $\tilde{l}<w$ of their income and issues bonds one period ahead that are claims on the tax proceeds $\tilde{l}$. Let $\pi$ be the number of newly born consumers per newly born entrepreneur. At date $t$, the government receives $\tilde{l} \pi /\left(1+r_{t+1}\right)$ from the bond issuance and distributes it to consumers. 
Then $l=\tilde{l} \pi$. By issuing debt and redeeming it by taxing newly born consumers, the government is able to increase the supply of outside liquidity.

As long as $1+r_{t+1}>1$, this policy makes consumers worse off. However, when condition (B) holds so that bubbles are possible, the government can issue debt and constantly roll it over without ever raising taxes: the bubble and government debt become isomorphic. Hence, a possible reinterpretation of the model is that the bubble is government debt. Under this interpretation, when liquidity is scarce-condition (B) holds - the government can increase the supply of outside liquidity at no cost to the government budget (without ever having to raise taxes).

\subsection{Interest-rate sensitive outside liquidity}

In this section, we provide some other micro-foundations for outside liquidity. In these other foundations, $l$ decreases with the interest rate. We show how to extend some of our most important results to this more general case.

5.3.1. Unconstrained firms. Suppose that there also exists a competitive fringe of firms operating a concave production function $f\left(k_{t}\right)$. These firms are owned by consumers who only consume when young. Consumers then sell the firms to investors for a price $f\left(k_{t}\right) /\left(1+r_{t}\right)-k_{t}$, where $k_{t}$ is the equilibrium investment level. In equilibrium, it will be the case that $f^{\prime}\left(k_{t}\right)=$ $1+r_{t}$ so that $k_{t}=k\left(r_{t}\right)$, where $k$ is decreasing in $r_{t}$. This creates a net positive supply of trees $l_{t}=l\left(r_{t}\right) \equiv f\left(k\left(r_{t}\right)\right)$.

5.3.2. Consumers as borrowers and securitization. Suppose that consumers have concave preferences and hence an elastic borrowing margin. They live for two periods and have preferences given by

$$
u\left(c^{y}\right)+\beta u\left(c^{o}\right)
$$

where $c^{y}$ and $c^{o}$ denote, respectively, consumption when young and old. They earn income $w^{y}$ when young and $w^{o}$ when old. To simplify the analysis, we focus on the case of log preferences where $u(c)=\log (c)$. In this case, consumers of generation $t$, facing interest rate $r_{t}$, consume

$$
c_{t}^{y}=\frac{1}{1+\beta}\left(w^{y}+\frac{w^{o}}{1+r_{t}}\right) \quad \text { and } \quad c_{t}^{o}=\frac{\beta}{1+\beta}\left(\left(1+r_{t}\right) w^{y}+w^{o}\right) .
$$

The supply of trees from the consumers' sector is therefore

$$
l_{t}=l\left(r_{t}\right) \equiv w^{o}-\frac{\beta}{1+\beta}\left(\left(1+r_{t}\right) w^{y}+w^{o}\right),
$$

where $l\left(r_{t}\right)$ is decreasing with $r_{t}$.

In this analysis, consumers do not face collateral constraints when they borrow. In practice, they often do; furthermore, the institutions that determine the extent to which claims on consumers' future income can be transformed into stores of value have high policy relevance. ${ }^{24}$

24. Suppose that consumers have some endowment of goods $w$-labour income-in their youth. They use that labour income to build a house, which has total value $y_{1} j_{t}$ at period $t+1$, where $j_{t}$ is the home investment realized in period $t$. However, suppose only a fraction $y_{0} j_{t}<y_{1} j_{t}$ can be collateralized. Consumers can invest up to $w /[1-$ $\left.y_{0} /\left(1+r_{t}\right)\right]$ in housing. Consumers thus create $l_{t}=l\left(r_{t}\right)$ additional stores of values for the corporate sector where $l\left(r_{t}\right) \equiv y_{0} w /\left[1-y_{0} /\left(1+r_{t}\right)\right]$. An increase in securitization-in the form of mortgage backed securities $e . g$. 一 can be formalized as an increase in $y_{0}$ towards $y_{1}$ and materializes as an increase in $l_{t}$. In this micro-foundation, the amount of trees $l\left(r_{t}\right)$ is again endogenous as it decreases with the interest rate. 
5.3.3. Generalizing the analysis to interest-sensitive outside liquidity. Let us now analyse a framework that encompasses all the examples mentioned above. There is a net supply of assets owned by another sector of the economy (which we call the consumers' sector) in the amount $l_{t}=l\left(r_{t}\right)$, where $l$ is decreasing in $r_{t}$.

The supply and demand equations for assets are now given by

$$
i_{t}=\frac{l_{t}+b_{t}+\rho_{0} i_{t-1}}{1-\frac{\rho_{0}}{1+r_{t+1}}} \quad \text { and } \quad i_{t}=\frac{A\left(1+r_{t+1}\right)-l_{t+1}-\left(1+r_{t+1}\right) b_{t}}{\rho_{0}} .
$$

The dynamics of this economy are harder to analyse because the endogeneity of $l_{t}$ imposes to keep track of an additional state variable in addition to $i_{t-1}$ and $b_{t}$ : the past level of the interest rate $r_{t}$. However, the steady-state analysis remains very tractable. In the bubbly steady state

$$
i^{* *}=\frac{A}{1-\rho_{0}}, \quad b^{* *}=A \frac{1-2 \rho_{0}}{1-\rho_{0}}-l(0), \quad \text { and } \quad r^{* *}=0 .
$$

Note that investment in the bubbly steady state is independent of the function $l\left(r_{t}\right)$. There is perfect crowding out between bubbles and trees: $b^{* *}+l(0)$ is independent of the function $l\left(r_{t}\right)$ away from zero interest rates.

The condition for the bubbly steady state becomes

$$
A \frac{1-2 \rho_{0}}{1-\rho_{0}}-l(0)>0 .
$$

We continue to denote investment and the interest rate that prevail at the bubble-free steady state by $i^{*}$ and $r^{*}$.

Proposition 10. Suppose that condition $\left(B^{\prime \prime \prime}\right)$ holds. Then the interest rate at the bubble-free steady state is negative: $r^{*}<0$.

(i) If $l\left(r^{*}\right)>0$, investment in the bubbly steady state $i^{* *}$ is higher than investment $i^{*}$ in the bubble-free steady state.

(ii) If $l\left(r^{*}\right)<0$ and $-\frac{1-\rho_{0}}{\rho_{0}} l\left(r^{*}\right)<\frac{A}{1-\rho_{0}}$, investment in the bubbly steady state $i^{* *}$ is lower than investment $i^{*}$ in the bubble-free steady state.

Remark 4. In the model with unconstrained firms, we have $l\left(r^{*}\right)=f\left(k^{*}\right)>0$. Proposition 10 then shows that $i^{* *}>i^{*}$. However, note that the steady-state investment level for unconstrained firms in a bubbly steady state is lower than that in the non-bubbly steady state: $k^{* *}<k^{*}$. This is the standard crowding-out effect of bubbles on investment emphasized in Tirole (1985) in the context of the model of Diamond (1965). Therefore, bubbles crowd in the investment of constrained firms $\left(i^{* *}>i^{*}\right)$ but crowd out the investment of unconstrained firms $\left(k^{* *}<k^{*}\right)$.

\section{CONCLUSION}

This paper suggests a number of promising research avenues. Three themes seem to us particularly interesting. First, we have only briefly touched in Section 4.2 on the question of who should hold the bubble. There we saw that a stochastic bubble is held in equilibrium by the firms with the lowest pledgeable income. To explore the ownership question further, one could e.g. allow less levered agents such as consumers to hold the bubble. Second, our model is too stylized to analyse the specific role of monetary policy or the interaction between prudential regulation and interest rate policy; developing the model along this dimension would be interesting. Third, it 
would be worth introducing the possibility of bailouts. In Farhi and Tirole (2012), we investigate this question and point out that systemic bailouts (e.g. through lax interest rate policy in response to a crisis) result in strategic complementarities in liquidity and portfolio choices. The financial institutions' incentive to correlate their positions on the overvalued assets would have implications for macrodynamics and public debt.

Our analysis has been deliberately theoretical. Its implications for public policy require further thought and extensions. Economies recurrently generate cycles of asset price overvaluations, credit booms, and, when bubbles burst, recessions. Potential applications to the measurement of capital adequacy abound. For example, asset price overvaluation and crashes are closely related to the policy debates on pro-cyclical regulation, fair value accounting, and deleveraging in busts. Similarly, an analysis of the link between bubbles and the scarcity of liquidity can shed light on public policies controlling the supply of outside liquidity, e.g. by adjusting the level of public debt or by tightening or relaxing securitization standards. Finally, this type of analysis can shed light on the link between bubbles and financial development. ${ }^{25}$ Our stance that policy implications lie outside the scope of our paper should not obscure the potential fruitfulness of such policy investigations.

\section{APPENDIX A}

\section{A.1. Proofs for Section 2}

Although we focus on the case $l \geq 0$ in the text, the derivations in this section are also valid when $l<0$. We make use of some of these results when we turn to the case $l<0$ in Section 5.1.

Derivation of the closed-form expressions for the policy functions $\Phi^{i}, \Phi^{r}$, and $\Phi^{b}$ in the bubble-free case. Assume that $b_{t}=0$. The system of two equations (equations (2) and (3)) in the two unknowns $\left(i_{t}, r_{t+1}\right)$ can be solved as follows. Using equation (3) to find an expression for $r_{t+1}$ and replacing this expression in equation (2), we are led to the following quadratic equation:

$$
i_{t}^{2}-\left[A+\rho_{0} i_{t-1}-l\left(\frac{1}{\rho_{0}}-1\right)\right] i_{t}-\frac{l\left(l+\rho_{0} i_{t-1}\right)}{\rho_{0}} .
$$

Given a solution to this equation, we can then compute the associated interest rate $1+r_{t+1}=\left(\rho_{0} i_{t}+l\right) / A$. The only solution of equation (A.1) with $i_{t} \geq 0$ and an associated interest rate such that $1+r_{t+1} \geq \rho_{0}$ is given by

$$
i_{t}=\frac{A+\rho_{0} i_{t-1}-\left(\frac{1}{\rho_{0}}-1\right) l+\sqrt{\left[A+\rho_{0} i_{t-1}-\left(\frac{1}{\rho_{0}}-1\right) l\right]^{2}+4 \frac{l}{\rho_{0}}\left(l+\rho_{0} i_{t-1}\right)}}{2} .
$$

Using the asset demand equation (3) we can compute the associated interest rate

$$
1+r_{t+1}=\rho_{0} \frac{A+\rho_{0} i_{t-1}+\left(1+\frac{1}{\rho_{0}}\right) l+\sqrt{\left[A+\rho_{0} i_{t-1}-\left(\frac{1}{\rho_{0}}-1\right) l\right]^{2}+4 \frac{l}{\rho_{0}}\left(l+\rho_{0} i_{t-1}\right)}}{2\left(A-b_{t}\right)} .
$$

Derivation of the bubble-free steady state. A steady state $\left(i^{*}, r^{*}\right)$ of the bubble-free economy solves

$$
i^{*}=\frac{l+\rho_{0} i^{*}}{1-\frac{\rho_{0}}{1+r^{*}}} \quad \text { and } \quad i^{*}=\frac{A\left(1+r^{*}\right)-l}{\rho_{0}} .
$$

This yields the following quadratic equation in $i^{*}$ :

$$
i^{* 2}\left(1-\rho_{0}\right)-i^{*}\left[A+l-\left(\frac{1}{\rho_{0}}-1\right) l\right]-\frac{l^{2}}{\rho_{0}}=0 .
$$

25. Financial development in our model is captured by the quality of governance $\left(\rho_{0}\right)$ and the existing stock of traded securities $\left(\rho_{0} i_{t-1}\right)$. 
This equation has two solutions. When $l \neq 0$, one of these solutions is strictly negative and the other one is strictly positive. The strictly positive solution is given by

$$
i^{*}=\frac{(A+l)-\left(\frac{1}{\rho_{0}}-1\right) l+\sqrt{\left[(A+l)-\left(\frac{1}{\rho_{0}}-1\right) l\right]^{2}+4 \frac{l^{2}}{\rho_{0}}\left(1-\rho_{0}\right)}}{2\left(1-\rho_{0}\right)} .
$$

Using $1+r^{*}=\left(\rho_{0} i^{*}+l\right) / A$, we can compute the associated interest rate $r^{*}$

$$
1+r^{*}=\rho_{0} \frac{A+\frac{l}{\rho_{0}}+\sqrt{\left[(A+l)-\left(\frac{1}{\rho_{0}}-1\right) l\right]^{2}+4 \frac{l^{2}}{\rho_{0}}\left(1-\rho_{0}\right)}}{2 A\left(1-\rho_{0}\right)} .
$$

When $l=0$, we have $1+r^{*}=\rho_{0} /\left(1-\rho_{0}\right)>\rho_{0}$. When $l>0$, we have $1+r^{*}>\rho_{0} /\left(1-\rho_{0}\right)$. This is obvious from the equation $i^{*}=l /\left(1-\rho_{0}-\rho_{0} /\left(1+r^{*}\right)\right)$. $^{26}$

With $l=0$, the second solution of equation (A.5) features positive (in fact zero) investment. It is given by $i^{*}=0$ and $1+r^{*}=0$. However, this does not correspond to a competitive equilibrium (which requires $1+r^{*} \geq \rho_{0}$ ).

Proof of Proposition 1. We know that the steady state is the unique intersection of the function $i \rightarrow \Phi^{i}(i, 0)$ with the identity function $i \rightarrow i$ on $[0, \infty)$. We can compute

$$
\Phi^{i}(0,0)=\frac{A-\left[\frac{1}{\rho_{0}}-1\right] l+\sqrt{\left\{A-\left[\frac{1}{\rho_{0}}-1\right] l\right\}^{2}+4 \frac{l^{2}}{\rho_{0}}}}{2}>0 .
$$

Similarly, $\Phi^{i}(i, 0) \sim_{i \rightarrow \infty} \frac{\rho_{0}}{2} i$. This ensures that $\Phi^{i}(i, 0)>i$ for $i$ low enough and $\Phi^{i}(i, 0)<i$ for $i$ high enough. Since there is a unique positive solution to $\Phi^{i}(i, 0)=i$, this proves that $\Phi^{i}(i, 0)>i$ for $i<i^{*}$ and $\Phi^{i}(i, 0)<i$ for $i>i^{*}$. Since, in addition, $\Phi^{i}(i, 0)$ is increasing in $i$, we have that $i^{*}>\Phi^{i}(i, 0)>i$ for $i<i^{*}$ and $i^{*}<\Phi^{i}(i, 0)<i$ for $i>i^{*}$. This ensures that this steady state is stable.

Proof that $r^{*}$ increases with $l$. We have

$$
\frac{d r^{*}}{d l}=\frac{\left(1+r^{*}\right)-\rho_{0}}{2 A\left(1-\rho_{0}\right) \sqrt{\left[A \rho_{0}+l\right]^{2}-4 A l\left(1-\rho_{0}\right) \rho_{0}}}>0 .
$$

\section{A.2. Proofs for Section 3}

Although we focus on the case $l \geq 0$ in the text, the derivations in this section are also valid when $l<0$, except for the proof of Proposition 3 which is specific to the case $l \geq 0$. We make use of some of these results when we turn to the case $l<0$ in Section 5.1 .

Derivation of the closed-form expressions for the policy functions $\Phi^{i}, \Phi^{r}$, and $\Phi^{b}$. The system of two equations (equations (2) and (3)) in the two unknowns $\left(i_{t}, r_{t+1}\right)$ can be solved as follows. Using equation (3) to find an expression for $r_{t+1}$ and replacing this expression in equation (2), we are led to the following quadratic equation:

$$
i_{t}^{2}-\left[A+\rho_{0} i_{t-1}-l\left(\frac{1}{\rho_{0}}-1\right)\right] i_{t}-\frac{l\left(l+b_{t}+\rho_{0} i_{t-1}\right)}{\rho_{0}} .
$$

Given a solution to this equation, we can then compute the associated interest rate $1+r_{t+1}=\left(\rho_{0} i_{t}+l\right) /\left(A-b_{t}\right)$. When $l \geq 0, b_{t}<A$ is a necessary condition for equilibrium. When $l<0$, we can have $b_{t}<A$ or $b_{t} \geq A$. Assume first that $b_{t}<A$. Then the only solution of equation (A.1) with $i_{t} \geq 0$ and an associated interest rate such that $1+r_{t+1} \geq \rho_{0}$ is given by $i_{t}=\Phi^{i}\left(i_{t-1}, b_{t}\right)$ where

$$
\Phi^{i}\left(i_{t-1}, b_{t}\right) \equiv \frac{A+\rho_{0} i_{t-1}-\left(\frac{1}{\rho_{0}}-1\right) l+\sqrt{\left[A+\rho_{0} i_{t-1}-\left(\frac{1}{\rho_{0}}-1\right) l\right]^{2}+4 \frac{l}{\rho_{0}}\left(b_{t}+l+\rho_{0} i_{t-1}\right)}}{2} .
$$

26. Note that the analysis extends to the case $l<0$. In this case, the function $l /\left[1-\rho_{0} /\left(1+r^{*}\right)-\rho_{0}\right]$ is convex and increasing. It increases from $-l / \rho_{0}$ to $+\infty$ on $\left(\rho_{0}, \frac{\rho_{0}}{1-\rho_{0}}\right)$. The function $\left[A\left(1+r^{*}\right)-l\right] / \rho_{0}$ is linear and increasing. It increases from $A-l / \rho_{0}>-l / \rho_{0}$ to $A /\left(1-\rho_{0}\right)-l / \rho_{0}$ on $\left(\rho_{0}, \frac{\rho_{0}}{1-\rho_{0}}\right)$. The unique intersection of these functions on $\left(\rho_{0}, \frac{\rho_{0}}{1-\rho_{0}}\right)$ is given by equations (A.5) and (A.6). Hence, $\rho_{0} /\left(1-\rho_{0}\right)>1+r^{*}>\rho_{0}$. 
Using the asset demand equation (3) we can compute the associated interest rate $1+r_{t+1}=1+\Phi^{r}\left(i_{t-1}, b_{t}\right)$, where

$$
1+\Phi^{r}\left(i_{t-1}, b_{t}\right) \equiv \rho_{0} \frac{A+\rho_{0} i_{t-1}+\left(1+\frac{1}{\rho_{0}}\right) l+\sqrt{\left[A+\rho_{0} i_{t-1}-\left(\frac{1}{\rho_{0}}-1\right) l\right]^{2}+4 \frac{l}{\rho_{0}}\left(b_{t}+l+\rho_{0} i_{t-1}\right)}}{2\left(A-b_{t}\right)}
$$

and the bubble in the next period $b_{t+1}=\Phi^{r}\left(i_{t-1}, b_{t}\right) \equiv\left[1+\Phi^{r}\left(i_{t-1}, b_{t}\right)\right] b_{t}$. These equations determine the policy function $\Phi^{i}, \Phi^{r}$, and $\Phi^{b}$ in closed form.

We now need to consider the case where $l<0$ and $b_{t} \geq A$. In this case, there is a solution to the quadratic equation (A.1) with $i_{t} \geq 0$ and $1+r_{t+1} \geq \rho_{0}$ if and only if $\left[A+\rho_{0} i_{t-1}-\left(\frac{1}{\rho_{0}}-1\right) l\right]^{2}+4 \frac{l}{\rho_{0}}\left(b_{t}+l+\rho_{0} i_{t-1}\right) \geq 0$ and $A-b_{t}-$ $\frac{l}{\rho_{0}}>b_{t}+l+\rho_{0} i_{t-1}$. When these conditions hold, equations (A.7) and (A.8) still represent one solution with $i_{t} \geq 0$ and $1+r_{t+1} \geq \rho_{0},{ }^{27}$ but there is now another solution given by

$$
i_{t}=\frac{A+\rho_{0} i_{t-1}-\left(\frac{1}{\rho_{0}}-1\right) l-\sqrt{\left[A+\rho_{0} i_{t-1}-\left(\frac{1}{\rho_{0}}-1\right) l\right]^{2}+4 \frac{l}{\rho_{0}}\left(b_{t}+l+\rho_{0} i_{t-1}\right)}}{2}
$$

and $1+r_{t+1}=\left(\rho_{0} i_{t}+l\right) /\left(A-b_{t}\right)$. We argue that this solution has undesirable characteristics and focus on the solution given by equations (A.7) and (A.8). Our motivation is that the other intersection displays perverse comparative statics: it has the unnatural feature that an upward shift in the asset demand curve leads to a decrease in $i_{t-1}$ and a decrease in the price $1 /\left(1+r_{t+1}\right)$. This is because this solution corresponds to a point where the asset demand curve crosses the asset supply curve from above at the intersection with the lowest value of $i_{t}$. By contrast, the asset demand curve crosses the asset supply curve from below at the solution given by equations (A.7) and (A.8).

Derivation of the $i_{t}=i_{t-1}$ and $b_{t+1}=b_{t}$ schedules. Imposing $i_{t}=i_{t-1}$ in equation (2), we find

$$
i_{t-1}\left(1-\rho_{0}-\frac{\rho_{0}}{1+r_{t+1}}\right)=l+b_{t} .
$$

Using equation (3), we can replace $1 /\left(1+r_{t+1}\right)$ in equation (A.9) by

$$
\frac{1}{1+r_{t+1}}=\frac{A-b_{t}}{l+\rho_{0} i_{t-1}} .
$$

This yields the following equation for the $i_{t}=i_{t-1}$ schedule:

$$
b_{t}=i_{t-1}^{2} \frac{\rho_{0}}{l}\left(1-\rho_{0}\right)-\frac{\rho_{0} i_{t-1}}{l}\left[A+\left(2-\frac{1}{\rho_{0}}\right) l\right]-l \text {. }
$$

Imposing $r_{t+1}=0$ in equation (2), we find

$$
i_{t}=\frac{l+b_{t}+\rho_{0} i_{t-1}}{1-\rho_{0}} .
$$

Imposing $r_{t+1}=0$ in equation (3) and imposing $r_{t+1}=0$, we find $A=l+\rho_{0} i_{t}+b_{t}$. Using equation (A.10) to replace $i_{t}$, this expression can be rearranged as follows:

$$
b_{t}=-\rho_{0}^{2} i_{t-1}+\left(1-\rho_{0}\right)(A-l)-\rho_{0} l,
$$

yielding the desired equation for the $b_{t+1}=b_{t}$ schedule.

A useful Lemma.

Lemma 2. The interest rate $r_{t+1}=\Phi^{r}\left(i_{t-1}, b_{t}\right)$ is increasing in $i_{t-1}$ and $b_{t}$.

The proof of this lemma is as follows. In the derivation of the closed-form expressions for the policy functions $\Phi^{i}$, $\Phi^{r}$, and $\Phi^{b}$, we proved the following: at the solution given by equations (A.7) and (A.8), the asset demand curve (3)

27. In the particular case where $b_{t}=A$, equation (A.7) gives $i_{t}=-l / \rho_{0}$. Both the numerator and the denominator in expression for $1+r_{t+1}$ in equation (A.8) are zero. The value of the interest rate is not pinned down by this equation. In this case, the value of the interest rate can be inferred from the asset supply equation

$$
1+r_{t+1}=\frac{\rho_{0} i_{t}}{i_{t}-\left(l+b_{t}+\rho_{0} i_{t-1}\right)}=\rho_{0} \frac{-\frac{l}{\rho_{0}}}{-\frac{l}{\rho_{0}}-\left(l+b_{t}+\rho_{0} i_{t-1}\right)} .
$$


crosses the asset supply curve (2) from below. Moreover, the asset supply curve is downward sloping. Since increases in $i_{t-1}$ shift the asset supply curve upwards without affecting the asset demand curve, increases in $b_{t}$ shift the asset supply curve upwards and the asset demand curve downwards. In both cases, the interest rate $r_{t+1}$ increases.

Proof of Lemmas 1 (and 3 in the Online Appendix). The properties of the interest rate $r_{t+1}=\Phi^{r}\left(i_{t-1}, b_{t}\right)$ are a direct consequence of Lemma 2. Let us turn to the properties of investment $i_{t}=\Phi^{i}\left(i_{t-1}, b_{t}\right)$. We can solve for investment $i_{t}$ as a function of $i_{t-1}$ and $b_{t}$

$$
i_{t}=\frac{A+\rho_{0} i_{t-1}+\left[1-\frac{1}{\rho_{0}}\right] l+\sqrt{\left\{A+\rho_{0} i_{t-1}+\left[1-\frac{1}{\rho_{0}}\right] l\right\}^{2}+4 \frac{l}{\rho_{0}}\left[b_{t}+l+\rho_{0} i_{t-1}\right]}}{2} .
$$

From this expression, it is clear that $i_{t}$ is increasing in $i_{t-1}$ and $b_{t}$ if $l>0$ and decreases with $b_{t}$ if $l<0$. The other results follow directly from these properties of $\Phi^{i}$ and $\Phi^{r}$.

The rest of Appendix A.2, with the proofs of Propositions 3 and 4 can be found online, together with Appendices A.3 and A.4.

Acknowledgment. We thank Fernando Alvarez, Marios Angeletos, Pol Antras, Gadi Barlevy, Ricardo Caballero, V.V. Chari, Gita Gopinath, Robert King, Anton Korinek, John Leahy, Guido Lorenzoni, Kiminori Matsuyama, Adriano Rampini, Guillaume Rocheteau, Kjetil Storesletten, Ivan Werning, Wei Xiong, four anonymous referees, and participants at various seminars and conferences for useful comments. The financial support of the FdR IDEI-SCOR research project "Market Risk and Value Creation" is gratefully acknowledged.

\section{Supplementary Data}

Supplementary data are available at Review of Economic Studies online.

\section{REFERENCES}

ABEL, A. B., MANKIW, N. G., SUMMERS, L. H. and ZECKHAUSER, R. J. (1989), “Assessing Dynamic Efficiency: Theory and Evidence", Review of Economic Studies, 56, 1-19.

ABREU, D. and BRUNNERMEIER, M. (2003), "Bubbles and Crashes", Econometrica, 71, 173-204.

ADRIAN, T. and SHIN, H. (2008), "Financial Intermediaries, Financial Stability and Monetary Policy" New-York Fed and Princeton (Paper presented at Jackson Hole; http://www.kansascityfed.org/publicat/sympos/2008/ shin.08.06.08.pdf).

AIYAGARI, R. (1994), “Uninsured Idiosyncratic Risk and Aggregate Saving”, Quarterly Journal of Economics, 109, 659-684.

ALLAIS, M. (1947), Economie et Intérêt (Paris: Imprimerie Nationale et Librairie des Publications Officielles).

ALLEN, F. and GALE, D. (2000), "Bubbles and Crises", Economic Journal, 110, 236-255.

ALLEN, F. and GORTON, G. (1993), "Churning Bubbles", Review of Economic Studies, 60, 813-836.

ALLEN, F., MORRIS, S. and POSTLEWAITE, A. (1993), "Finite Bubbles with Short-Sale Constraints and Asymmetric Information", Journal of Economic Theory, 61, 206-230.

AZARIADIS, C. (1993), Intertemporal Macroeconomics (Cambridge: Blackwell).

BALASKO, Y. and SHELL, K. (1981), "The Overlapping Generations Model II: The Case of Pure Exchange with Money", Journal of Economic Theory, 24, 112-142.

BARLEVY, G. (2009), "A Leverage-based Model of Speculative Bubbles” (Working Paper, Federal Reserve Bank of Chicago; www.econ.wisc.edu/workshop/leveragebubbles.pdf).

BERNANKE, B. (2002), “Asset Price 'Bubbles' and Monetary Policy”, Remarks before the New York Chapter of the National Association for Business Economics (New York), 15 October.

BERNANKE, B. (2005), "The Global Saving Glut and the U.S. Current Account Deficit", Sandridge Lecture, Virginia Association of Economics (Richmond: Federal Reserve Board; http://www.federalreserve.gov/boarddocs/speeches/ 2005/200503102/).

BERNANKE, B. and GERTLER, M. (1989), “Agency Costs, Net Worth, and Business Fluctuations", American Economic Review, 79, 14-31.

BERNANKE, B. and GERTLER, M. (2000), "Monetary Policy and Asset Price Volatility” (Working Paper No. 7559, NBER).

BERNANKE, B. and GERTLER, M. (2001), "Should Central Banks Respond To Movements in Asset Prices?", American Economic Review, Papers and Proceedings, 91, 253-257.

BEWLEY, T. (1986), "Stationary Monetary Equilibrium with a Continuum of Independently Fluctuating Consumers", in Hildenbrand, W. and Mas-Colell, A. (eds) Contributions to Mathematical Economics in Honor of Gérard Debreu (Amsterdam: North Holland) 79-102. 
BORDO, M. and JEANNE, O. (2002), "Boom-Busts in Asset Prices, Economic Instability, and Monetary Policy" (Working Paper No. 8966, NBER).

CABALLERO, R. J., FARHI, E. and GOURINCHAS, P. O. (2008a), "An Equilibrium Model of Global Imbalances and Low Interest Rates", American Economic Review, 98, 358-393.

CABALlERO, R. J., FARHI, E. and GOURINCHAS, P. O. (2008b), "Financial Crash, Commodity Prices, and Global Imbalances", Brookings Papers on Economic Activity, 2, 1-55.

CABAlLERO, R. and KRISHNAMURTHY, A. (2006), "Bubbles and Capital Flow Volatility: Causes and Risk Management", Journal of Monetary Economics, 53, 35-53.

CASS, D., OKUMO, M. and ZILCHA, I. (1979), "The Role of Money in Supporting Pareto Optimality of the Competitive Equilibrium in Consumption Loan Type Models", Journal of Economic Theory, 11, 41-80.

CONLON, J. (2004), "Simple Finite Horizon Bubbles Robust to Higher Order Knowledge", Econometrica, 72, 927-936.

DIAMOND, P. (1965), "National Debt in a Neoclassical Growth Model", American Economic Review, 55, 1126-1150.

DOBLAS-MADRID, A. (2009), "A Robust Model of Bubbles with Multidimensional Uncertainty" (Working Paper, Michigan State University; http://www.um.es/analisiseco/seminarios/2010/antonio-doblas.pdf).

FARHI, E. and TIROLE, J. (2012), "Collective Moral Hazard, Maturity Mismatch and Systemic Bailouts", American Economic Review, forthcoming.

GALE, D. (1973), "Pure Exchange Equilibrium of Dynamic Economic Models", Journal of Economic Theory, 5, 12-36.

GILCHRIST, S. and LEAHY, J. (2002), "Monetary Policy and Asset Prices", Journal of Monetary Economics, 49, 75-97.

GRANDMONT, J. M. (1985), “On Endogenous Competitive Business Cycles”, Econometrica, 53, 995-1045.

GROSSMAN, G. M. and YANAGAWA, N. (1993), "Asset Bubbles and Endogenous Growth", Journal of Monetary Economics, 31, 3-19.

HAHN, F. (1982), Money and Inflation (Oxford: Basil Blackwell).

HIRANO, T. and YANAGAWA, N. (2010), "Asset Bubbles, Endogenous Growth, and Financial Frictions" (Mimeo, University of Tokyo; http://kiea21.or.kr/conference_eng/data201007/j/yanagawa-full.pdf).

HOLMSTRÖM, B. and TIROLE, J. (1998), "Private and Public Supply of Liquidity", Journal of Political Economy, 106, $1-40$.

KING, I. and FERGUSON, D. (1993), "Dynamic Inefficiency, Endogenous Growth, and Ponzi games", Journal of Monetary Economics, 32, 79-104.

KIYOTAKI, N. and MOORE, J. (1997), "Credit Cycles", Journal of Political Economy, 105, 211-248.

KIYOTAKI, N. and MOORE, J. (2008), "Liquidity, Business Cycles and Monetary Policy” (Mimeo Princeton and LSE; http://www.princeton.edu/ kiyotaki/papers/ChiKM6-1.pdf).

KOCHERLAKOTA, N. (2009), "Bursting Bubbles: Consequences and Cures” (Mimeo, University of Minnesota; http:// www.imf.org/external/np/seminars/eng/2009/macro/pdf/nk.pdf).

LEROY, S. (2004), "Bubbles and the Intertemporal Government Budget Constraint", Economic Bulletin, 5, 1-6.

LAGOS, R. and WRIGHT, R. (2005), "A Unified Framework for Monetary Theory and Policy Analysis", Journal of Political Economy, 113, 463-484.

NOSAL, E. and ROCHETEAU, G. (2011), A Search Approach to Money, Payments, and Liquidity (MIT Press).

OLIVIER, J. (2000), “Growth-Enhancing Bubbles”, International Economic Review, 41, 133-151.

ROCHETEAU, G. and WRIGHT, R. (2005), "Money in Search Equilibrium, in Competitive Equilibrium, and in Competitive Search Equilibrium”, Econometrica, 73, 175-202.

ROCHETEAU, G. and WRIGHT, R. (2010), "Liquidity and Asset Market Dynamics" (Mimeo, University of CaliforniaIrvine and University of Wisconsin-Madison; http://www.grocheteau.com/wpapers/RW_090210.pdf).

SAINT-PAUL, G. (1992), "Fiscal Policy in an Endogenous Growth Model", Quarterly Journal of Economics, 107, 1243-1260.

SAINT-PAUL, G. (2005), "Fiscal Policy and Economic Growth: The Role of Financial Intermediation", Review of International Economics, 13, 612-629.

SAMUELSON, P. A. (1958), "An Exact Consumption-Loan Model of Interest with or without the Social Contrivance of Money", Journal of Political Economy, 66, 467-482.

SANTOS, M. S. and WOODFORD, M. (1997), "Rational Asset Pricing Bubbles", Econometrica, 65, 19-58.

SCHEINKMAN, J. and XIONG, W. (2003), "Overconfidence and Speculative Bubbles", Journal of Political Economy, 111, 1183-1220.

TIROLE, J. (1985), “Asset Bubbles and Overlapping Generations”, Econometrica, 53, 1499-1528.

VENTURA, J. (2003), "Bubbles and Capital Flows" (Discussion Paper No. 3657, CEPR).

WALLACE, N. (1980), "The Overlapping Generations Model of Fiat Money", in Kareken, J. and Wallace, N. (eds) Models of Monetary Economies (Minneapolis: Federal Reserve Bank) 49-82.

WEIL, P. (1987), "Confidence and the Real Value of Money in an Overlapping Generations Economy", Quarterly Journal of Economics, 102, 1-22.

WILLIAMSON, S. and WRIGHT, R. (2011), "New Monetarist Economics: Models", in Friedman, B. and Woodford, M. (eds) Handbook of Monetary Economics, forthcoming.

WOODFORD, M. (1990), "Public Debt as Private Liquidity", American Economic Review, 80, 382-388. 